\title{
Reading and Spelling Development in Persian from Grade 1 to Grade 4
}

\author{
A thesis submitted to the Faculty of Graduate Studies and Research \\ In partial fulfillment of the requirements for the degree of \\ Doctor of Philosophy
}

by

Noriyeh Rahbari

Department of Psychology

Carleton University

Ottawa, Ontario

September 2008

(C) Noriyeh Rahbari 2008 


$\begin{array}{ll}\begin{array}{l}\text { Library and } \\ \text { Archives Canada }\end{array} & \begin{array}{l}\text { Bibliothèque et } \\ \text { Archives Canada }\end{array} \\ \begin{array}{l}\text { Published Heritage } \\ \text { Branch }\end{array} & \begin{array}{l}\text { Direction du } \\ \text { Patrimoine de l'édition }\end{array} \\ \begin{array}{l}\text { 395 Wellington Street } \\ \text { Ottawa ON K1A 0N4 } \\ \text { Canada }\end{array} & \begin{array}{l}\text { 395, rue Wellington } \\ \text { Ottawa ON K1A 0N4 } \\ \text { Canada }\end{array}\end{array}$

Your file Votre référence ISBN: 978-0-494-43906-7

Our file Notre référence

ISBN: 978-0-494-43906-7

NOTICE:

The author has granted a nonexclusive license allowing Library and Archives Canada to reproduce, publish, archive, preserve, conserve, communicate to the public by telecommunication or on the Internet, loan, distribute and sell theses worldwide, for commercial or noncommercial purposes, in microform, paper, electronic and/or any other formats.

The author retains copyright ownership and moral rights in this thesis. Neither the thesis nor substantial extracts from it may be printed or otherwise reproduced without the author's permission.
AVIS:

L'auteur a accordé une licence non exclusive permettant à la Bibliothèque et Archives Canada de reproduire, publier, archiver, sauvegarder, conserver, transmettre au public par télécommunication ou par l'Internet, prêter, distribuer et vendre des thèses partout dans le monde, à des fins commerciales ou autres, sur support microforme, papier, électronique et/ou autres formats.

L'auteur conserve la propriété du droit d'auteur et des droits moraux qui protège cette thèse. $\mathrm{Ni}$ la thèse ni des extraits substantiels de celle-ci ne doivent être imprimés ou autrement reproduits sans son autorisation.
In compliance with the Canadian Privacy Act some supporting forms may have been removed from this thesis.

While these forms may be included in the document page count, their removal does not represent any loss of content from the thesis.
Conformément à la loi canadienne sur la protection de la vie privée, quelques formulaires secondaires ont été enlevés de cette thèse.

Bien que ces formulaires aient inclus dans la pagination, il n'y aura aucun contenu manquant.

\section{Canada}




\begin{abstract}
In the present study we investigated the relative importance of phonological and orthographic skills in Persian children's reading and spelling development. Persian has a mixed orthography that allows one to study within one language characteristics typically found in shallow orthographies as well as those found in deeper orthographies. Reading and spelling latencies and error rates of words and nonwords were measured in a sample of 140 monolingual Persian children (mean age $=9 ; 02, \mathrm{SD}=13.28 \mathrm{mo}$ ) attending Grades 1 to 4 in Iran. The word stimuli differed in terms of reading transparency (transparent vs. opaque) and spelling polygraphy (nonpolygraphic phonemes vs. polygraphic phonemes). The nonwords were transparent and nonpolygraphic. The reading results showed that children, except those in Grade 1, read transparent words faster than nonwords. However, opaque words (words with missing vowels) were never read faster than nonwords. In addition, transparent words were read faster and more accurately than opaque words in all grades. These findings suggest that while use of orthographic skills was dominant in transparent word reading, phonological skills played an important role in opaque word reading. The spelling results failed to show a word-advantage effect, that is, there was not a significant difference in spelling nonpolygraphic words and nonwords and polygraphic words were spelled less accurately and more slowly than nonwords. These results suggest that Persian children relied on phonological skills to spell words. Taken together, the findings showed that reading and spelling in Persian rely on different underlying skills, although they show the same accuracy levels when controlling for consistency level in terms of reading and spelling.
\end{abstract}




\section{Acknowledgements}

First and foremost, my sincere appreciations and thanks go to my thesis supervisor Dr. Monique Sénéchal to her professional and thorough supervision. Her invaluable guidance and support are what got me here today and without her support I would never had been able to achieve my goals and dreams. I cannot possibly quantify the importance of her academic guidance and valuable advice over the past few years.

I would also like to thank Dr. Jo-Anne LeFevre, Dr. John Logan for their guidance and help improve this research and my external examiner Dr. Debra Jared for her insightful feedback.

I would like to extend my thanks to my very good friend Soheyla Shamkali for her efforts and time doing pilot examinations, and Narges Arab-Moghaddam for collecting data for word frequencies, as well as all children and staff who contributed time to this research in Iran. I am also thankful to Mark Tovey for his time to familiarize me with computer programs used in this project. Many thanks to Caleb Lloyd, for the time and effort he put into reading the manuscript and providing me with very helpful comments.

I also greatly appreciate Carleton University and the Department of Psychology for the financial support during my doctoral program.

Finally, I would like to express my deepest thanks to my family, especially my extreme admiration and appreciation go to my sister Niloofar for her enduring support, and my mother, whose support and encouragement throughout the years are what formed the foundation of my work. 


\section{Table of Contents}

I. Introduction: Research Problem and Importance

II. Reading and Spelling Development 4

Introduction: Underlying Skills 4

How are Phonological and Orthographic Skills Measured? 6

Developmental Models of Literacy Acquisition $\quad 8$

$\begin{array}{lr}\text { Frith's Stage Model } & 8\end{array}$

Ehri's Phase Model 9

Literature Review: Reading and Spelling across Languages 11

Orthographic Depth Hypotheses $\quad 11$

Skills Used to Read 12

$\begin{array}{ll}\text { Skills Used to Spell } & 17\end{array}$

The Characteristics of the Persian Orthographic System 21

Reading and Spelling in Persian $\quad 26$

III. Associations between Reading and Spelling 30

Introduction: Nature and Direction of the Relation $\quad 30$

Is Spelling Harder than Reading? 32

IV. The Present Study: Summary and Hypotheses 36 
$\begin{array}{ll}\text { V. Method } & 39\end{array}$

$\begin{array}{lr}\text { Participants } & 39\end{array}$

$\begin{array}{ll}\text { Measures } & 40\end{array}$

Word Stimuli $\quad 41$

Word type 41

$\begin{array}{ll}\text { Word selection and characteristics } & 41\end{array}$

Nonword Stimuli $\quad 43$

Procedure and Apparatus $\quad 44$

$\begin{array}{ll}\text { VI. Results } & 47\end{array}$

$\begin{array}{ll}\text { Reading Performance } & 47\end{array}$

Analyses based on latencies $\quad 49$

Analyses based on error rates $\quad 52$

Word frequency $\quad 54$

Spelling Performance $\quad 55$

Analyses based on latency $\quad 55$

$\begin{array}{ll}\text { Analyses based on error rates } & 57\end{array}$

$\begin{array}{ll}\text { Word frequency } & 60\end{array}$

Difficulty Level between Reading and Spelling $\quad 60$

Degree of Spelling Inconsistencies $\quad 63$

$\begin{array}{ll}\text { VII. Discussion } & 66\end{array}$

Skills Used to Read Persian $\quad 66$

Skills Used to Spell Persian $\quad 73$

Relative difficulty level between Persian reading and spelling 81

Limitation and suggestion for future research $\quad 84$

$\begin{array}{lr}\text { Conclusion } & 85\end{array}$ 
References

Appendices 
List of Tables

Table 1. Mean, Frequency, and Duration of Words as a Function of Reading Transparency and Spelling Consistency

Table 2. Mean Correct Latencies in Milliseconds and Mean Percentages of Error Rates for Transparent Word, Opaque Word and Nonword Reading for Grades 1 to 4

Table 3. Mean Correct Latencies in Milliseconds and Mean Percentages of Error Rates for Polygraphic Word, Nonpolygraphic Word, and Nonword Spelling for Grades 1 to 4

Table 4. Mean Correct Latencies in Milliseconds and Mean Percentages of Error Rates for Polygraphic Words with One Polygraphic Letter and Polygraphic Words with Two Polygraphic Letters Spelling for Grades 1 to 4 


\section{List of Figures}

Figure 1. Short Vowel Selection in Persian Opaque Words

Figure 2. Polygraphic Letters Selection in Persian Polygraphic Words

Figure 3. Interaction between Consistency across Reading and Spelling Tasks 


\section{List of Appendices}

Appendix A. List of Real Words for Reading and Spelling with Word Frequencies, 103 and Durations

$\begin{array}{ll}\text { Appendix B. List of Nonwords for Reading and Spelling } & 105\end{array}$

$\begin{array}{ll}\text { Appendix c. Persian Alphabet } & 106\end{array}$ 


\section{Reading and Spelling Development in Persian from Grade 1 to Grade 4}

\section{Introduction: Research Problem and Importance}

Reading and spelling are two abilities that constitute the foundation of literacy acquisition (Fletcher-Flinn, Shankweiler \& Frost, 2004). It is, therefore, important to understand how these abilities are learned; what types of cognitive skills underlie the development of these abilities; how these two abilities are related to each other; whether the same skills are applied to develop both reading and spelling abilities; and finally, what the similarities and differences in learning to read and spell are among different orthographic systems. Finding the answer to these questions will be helpful from both pedagogical and psycholinguistic viewpoints.

Although some of these issues have been addressed in the literature on literacy development, others have been either controversial or have not been investigated directly and deeply yet. In addition, most theories and empirical research have been based on the reading and spelling acquisition of English-speaking children. Consequently, any detailed investigation of skills used by children learning to read in other languages is of interest. There are a number of important questions regarding the role of orthography in learning to read and spell, and Persian is a language that has received little attention. Studying commonalities and differences in literacy development across languages is helpful to distinguish between universal and language-specific aspects of this important cognitive process.

The first objective of the present study was to investigate the skills used to read and spell Persian at different age levels. The second objective was to compare Persian reading and spelling to understand whether Persian children show the same accuracy levels for both reading and spelling. More clearly the questions were: 1) What is the 
relative importance of phonological and orthographic skills in Persian reading and spelling development as children progress from Grades 1 to 4 ? 2) What is the relative difficulty level between reading and spelling in Persian?

The present research presents some advantages in comparison to other research that has investigated reading and spelling development. First, most of the previous studies on children's reading and spelling development have either examined children's reading and spelling development separately, or, if they studied these abilities together, more focus has been given to the children's reading development than their spelling. The relation between reading and spelling, particularly, the comparative difficulty level of these abilities has not been investigated directly. Moreover, to date, the proposed study is the first study that measures children's reading and spelling latencies together with error rates to evaluate changes in these abilities from Grades 1 to 4 . In addition, the unique characteristics of Persian permitted the investigation of children's reading and spelling of words that differed on complexity levels. Persian is a mixed orthography that allows one to study within one language characteristics typically found in shallow orthographies as well as those found in deeper orthographies. It is expected that this monolingual study of Persian children provides information about the language specific aspects and universal characteristics of reading and spelling.

The introduction to the present research is presented in two parts. The first part is an overview of the underlying skills used to read and spell and the second part discusses the relation between reading and spelling. In the first part, I explain the important role of two essential skills, namely, phonological and orthographic skills, on children's reading and spelling development and describe the methods typically used to measure these 
skills. Some important models of reading and spelling development are compared to understand the contribution of phonological and orthographic skills to reading and spelling in English as well as in other languages. Moreover, the cross-orthographic and other empirical findings are reviewed to address the skills used to read and spell in relatively consistent orthographic systems. Finally, the Persian orthographic system is described, and studies on Persian reading and spelling are reviewed.

In the second part of the introduction, I concentrate on the relation between reading and spelling. The main purpose of this last section is to explore potential factor(s) that may cause discrepancies in difficulty level between reading and spelling. Finally, after presenting a brief summary of the present study, the methodology is described in detail followed by results and discussion of findings 


\section{Reading and Spelling Development}

\section{Introduction: Underlying Skills}

Phonological and orthographic skills are the most crucial skills that underlie children's reading and spelling development. The role of other factors such as orthographic redundancies (i.e., body neighbours, Perry \& Zeigler, 2004), morphological knowledge (Treiman, Cassar, \& Zukowski, 1994) and analogies (e.g., Goswami, 1988; Marsh, Desberg, \& Cooper, 1997) have also been studied in English and a few other orthographic systems. The present review focused on the important role of phonological and orthographic skills in children's reading and spelling development because of the very limited research in Persian.

Phonological processing has been described with various terms such as phonemeto-grapheme/grapheme-to-phoneme conversions, cipher reading, sub-lexical route, indirect accessing, phonological recoding or decoding skills. A child with phonological skills has the ability to use grapheme-to-phoneme (GP) conversion rules to read words. Readers with phonological skills convert a letter or a combination of letters into the equivalent sounds and then blend the sounds to read the words. In terms of spelling, phoneme-to-grapheme conversions allow a child to segment the sounds in the words and represent the sound with the corresponding graphemes (Ehri, 1992).

Phonological skills are strongly predictive of successful reading and spelling acquisition across languages (e.g., Bradley \& Bryant, 1983; Lundberg, Olofsson, \& Wall, 1980; Snowling, 2000; Stanovich \& Siegel, 1994). In a longitudinal study with 6 and 7 year-old English-speaking children, proficiencies in two phonological tasks (segmentation and blending) strongly predicted successful reading (Perfetti, Beck, \& 
Hughes, 1987). In addition, a large number of studies have shown that good phonological knowledge characterized good readers, whereas poor phonological skills characterized poor readers (Adams, 1990; Goswami \& Bryant, 1990; Juel, 1988). Juel (1988) reported a probability of $88 \%$ that a child with poor phonological skills in Grade 1 will remain a poor reader and a poor speller in Grade 4. Indeed, it is argued that phonological skills act as a self-teaching method (Share, 1995). Phonological skills enable children to read and spell thousands of words that they have heard but never seen before (Bowey \& Muller, 2005; Ehri, 1992; Share, 1999).

When words become practiced enough phonologically they are stored in lexical memory (Ehri, 1992). It should be noted that practice by itself without sufficient phonological skills does not lead to storing words in the lexicon. In a study with skilled and less skilled readers, it was shown that practice did not enable the less skilled readers, who had poor phonological skills, to improve their word identification speeds (Ehri, \& Wilce 1983). According to Ehri and Wilce (1983) if a child failed to recognize the relations between letters and their associated sounds, then she/he should have problem "unitizing" spelling with pronunciation in lexical memory which should limit their word identification speed. Therefore, efficient phonological skills are necessary to develop orthographic skills (Share, 1995, 1999; Share \& Stanovich, 1995).

Although phonological skills are essential in early reading and spelling acquisition, phonological processing is usually slow and effortful. Moreover, reliance on phonological skills may not yield correct spelling in many cases (e.g., Treiman, 1993; Treiman et al., 1994). Fluency and speed in word identification have been shown to be critically important prerequisites for adequate reading comprehension (Perfetti, 1985). In 
order to understand a text, children need to identify the words quickly and automatically in a text. In this stage of word reading and spelling, a child retrieves the entire spelling of a word from his/her memory. This is called orthographic processing. Orthographic processing is usually characterized by high accuracy, speed, and automaticity (Ehri \& Wilce, 1983). Orthographic skills should be, however, distinguished from logographic (Frith, 1985) and visual cues (Ehri, 1994) whereby young children guess or recognize a few words based on the salient feature of a word. Researchers use terms such as sightword reading, direct visual accessing, lexical accessing, retrieval strategies, and word specific knowledge to describe orthographic processing.

A child with normal development of orthographic information moves from processing letters to processing letter sequences (e.g., words). Children with orthographic skills are sensitive to letter organization and spatial position patterns of letters in written words (Corcos \& Willows, 1993). Orthographic processing is a way of reading (Stanovich, 1980) and spelling (e.g., Barry, 1994; Kwong \& Varnhagen, 2005) that distinguishes skilled readers from less skilled readers.

\section{How are Phonological and Orthographic Skills Measured?}

Researchers studying children's literacy development have used both correlational and experimental methods to study phonological and orthographic skills. In correlational studies, a participant's scores on nonword reading are usually used as a measure of phonological skills. To measure orthographic skills, there are several methods. For instance orthographic skills can be assessed by using an orthographic judgment task in which children have to decide which of two phonemically equivalent spellings of a word (e.g., 'rane' versus 'rain') is the correct spelling (e.g., Olson, Wise, Connert, Rack, \& 
Fulker, 1989). In experimental studies, phonological and orthographic skills usually, are measured by a comparison between latencies and/or error rates for different types of stimuli. Using latencies to determine skills used to read or spell seems to be an accurate measure of phonological and orthographic processing because accuracy and speed are two important characteristics that differentiate orthographic skills from phonological skills.

Two well known indices used in experimental research to assess use of phonological and orthographic skills are lexicality and transparency effects. A lexicality effect is obtained from the comparison between performance on words and nonwords. Lexicality effects refer to the finding that reading real words is faster and more accurate than reading nonwords (Kinoshita, Lupker, \& Rastle, 2004). Because nonwords obligatorily do not have an orthographic representation to rely on, consequently, require phonological processes to be read or spelled. Therefore, if phonological skills are used to read both real words and nonwords, there should be no lexicality effect. However, if orthographic skills are applied to read real words, a lexicality effect is observed. That is, words are read more quickly and accurately than nonwords.

The term opaque words is used to describe words without one-to-one graphemeto-phoneme correspondences whereas the term transparent words is used to describe words with one-to-one mappings between graphemes and phonemes. Transparency effects refer to the finding that words that do not follow one-to-one correspondences between graphemes and phonemes are read less accurately and more slowly than words in which each grapheme corresponds to a single phoneme (Baluch \& Besner, 2001). To read and spell opaque words correctly, orthographic skills have to be applied. If 
phonological skills are applied, opaque words are read incorrectly and take longer to be processed compared to transparent words.

\section{Developmental Models of Literacy Acquisition}

\section{Frith's Stage Model}

According to stage models of literacy development, phonological and orthographic skills are acquired as a sequence of stages. Frith (1985) suggested that early reading development proceeds in three successive stages: A visual logographic stage is followed by an alphabetic or phonological stage, which, in turn, is followed by an orthographic stage. Frith argued that an orthographic strategy is distinguished from an alphabetic strategy by operating on larger units and by being non-phonological. According to Frith, beginning readers first rely on the phonological skills and then switch to orthographic procedures. Although Frith's developmental model emphasizes the role of phonological skills as important in early literacy development and the dominant role of orthographic skills later on, she assumes separate routes for phonological and orthographic skills.

Frith proposed the same stages for spelling development, but she stressed that phonological skills are more important in spelling than in reading (Frith, 1979). Moreover, she has argued that orthographic spelling comes later after orthographic representations become more precise in reading. According to this view, it is only during the orthographic stage that children can reliably spell irregular or inconsistent words. Similarly, spelling new words using analogies to previously learned words can only happen at the orthographic stage when lexical representations are fully specified. 
However, some researchers do not agree with one of the key assumptions of Frith's stage model that proposes children in the phonological stage initially use small units and only later use larger units such as morphemes or analogies based on word rimes. Goswami and Bryant (1990) argued that phonological development can progress from large units to small units; in addition, they argue that children can generally learn syllable and onset-rime levels before learning to decode phonemes when they are taught to read and write (Goswami \& Bryant, 1990). Goswami $(1993,1990)$ presented evidence indicating that children in the earliest stages of learning made analogies between shared rimes before they could decode phonemes. Therefore, these researchers believe children are able to learn based on orthographic processing from the beginning.

\section{Ehri's Phase Model}

Ehri (1994) proposed a model in which reading and spelling development is acquired in four phases including a visual-cue phase (pre-alphabetic phase), a phoneticcue phase (partial alphabetic phase), an alphabetic phase and, finally, an orthographic phase (consolidated phase). In the alphabetic phase, children make a complete connection between letters in written words and the phonemes detected in their pronunciation. One characteristic that distinguishes between the full and partial alphabetic phases is a child's ability to read words they never have read before (Ehri \& Wilce, 1987). Children's ability to read unfamiliar words enables them to remember complete information about the orthography of a rapidly growing number of sight words. According to Ehri (1994), when children gain sufficient experience with print they become able to read letter patterns, syllables, onset-rimes and whole words in the so-called orthographic phase. She believes that phonological and orthographic skills develop dependently and phonological skills are 
a prerequisite for the development of orthographic skills. This notion is also supported by many other theoretical and empirical findings (e.g., Bowey \& Muller, 2005;

Cunningham, Perry, Stanovich \& Share, 2004; Kyte, \& Johnson, 2006; Share, 1995;

1999; Share \& Stanovich, 1995).

There are some differences between the stage and phase models. The major difference between Frith's model and Ehri's model is the role of phonological skills in the final stage (i.e., orthographic stage) of reading development. Frith (1985) considers the orthographic stage as non-phonological, whereas Ehri (1994) considers it as a phase when grapheme-phoneme correspondence and orthographic knowledge are used. For Ehri, sight word reading involves establishing visual-phonological access routes rather than only visual routes into the mental lexicon. This means that reading sight words from memory still involves phonological processing to access the words (Ehri, 2005). Another difference between Frith and Ehri is the use of the terms stages and phases. A stage model (Frith, 1985) requires each stage to be a prerequisite for the next stage, whereas in a phase model, word reading in the pre-alphabetic phase does not contribute to word reading during later phases of reading and spelling (Ehri, 2005).

In sum, both models agree that the acquisition of both orthographic skills based on whole word recognition and phonological processing based on grapheme-to-phoneme (GP) or phoneme-to-grapheme (PG) correspondences are necessary for reading and spelling acquisition, although there are some disagreements regarding the developmental relation between these two skills.

The two models, however, have been proposed to account for only Englishspeaking children's reading and spelling acquisition. There are a number of theoretical 
and practical questions regarding the important role of orthographic systems in learning to read and spell. Some authors (e.g., Sprenger-Charolles, 2003) argue that if phonological skills play a role in literacy acquisition, this acquisition should be influenced by the degree of consistency of the grapheme-to-phoneme and phoneme-tographeme correspondences among different orthographic systems. Therefore, it is questioned whether these models proposed for English, a relatively opaque orthography, can be applied to other languages that have transparent orthographic systems.

\section{Literature Review: Reading and Spelling across Languages}

\section{Orthographic Depth Hypotheses}

Theories of orthographic depth explain how children's literacy acquisition is affected by the degrees of orthographic inconsistencies among languages (e.g., Frost, Katz \& Bentin, 1987; Seymour, Aro, \& Erskine, 2003; Wydell \& Butterworth, 1999). Indeed, languages differ based on their orthographic transparency. In transparent orthographic systems, the relation between grapheme and phoneme is straightforward, and grapheme-phoneme correspondences are highly predictable as is the case in Finnish, Italian, Spanish, and Turkish. There are languages, however, where the relation between grapheme and phoneme is not straightforward and each grapheme may correspond to many phonemes and/or each phoneme may be represented by more than one grapheme (e.g., English).

According to orthographic depth models, literacy acquisition is faster in languages with transparent orthographies than opaque orthographic systems (e.g., Seymour, et al., 2003). In addition, the degree of orthographic transparency is assumed to 
influence the processes used to read (e.g., Frost, et al., 1987; Katz \& Feldman, 1983; Katz \& Frost, 1992). That is, reliance on phonological and orthographic skills depends on a language's orthographic system. In languages with relatively transparent orthographic systems, readers rely to a larger extent on phonological processing because graphemephoneme correspondences are easily available in these languages as compared to deep orthographies.

A similar hypothesis is postulated by the psycholinguistic-grain-size hypothesis. The psycholinguistic-grain-size hypothesis posits that reading in transparent orthographies involves small linguistic units such as grapheme-to-phoneme mappings, whereas reading in opaque orthographic systems additionally requires the use of larger units (Goswami, Ziegler, Dalton, \& Schneider, 2003). According to this hypothesis, development of both small-size and large-size units in opaque orthographies is inevitable because small grain sizes are highly inconsistent (Perry \& Ziegler, 2000). Consequently, the readers of opaque orthographies are pushed to rely on a variety of psycholinguistic grain sizes including whole word, orthographic units corresponding to rhyme and grapheme-phoneme correspondences. Consequently, the need to switch between different grain-size levels results in higher errors and low reading speed in opaque orthographies in comparison to a transparent orthography in which the readers rely only on graphemephoneme correspondences.

\section{Skills Used to Read}

Two questions addressed in the research on reading in different orthographies include: (a) does the transparency of an orthography affect children's reading accuracy 
levels and rate of reading development? and (b) is the pattern of skills used to read also influenced by inconsistencies of orthographic systems?

There are numerous cross-orthographic studies showing that children learning to read in transparent orthographies acquire reading faster and show higher levels of accuracy in comparison to the children learning to read in opaque orthographies (e.g., Bruck, Genesee, \& Caravolas, 1997; Goswami et al., 2003). For instance, Aro and Wimmer (2003) reported that children learning to read in transparent orthographies such as French, German, Dutch, Spanish and Finnish reached a reading accuracy ranging between $85 \%$ and $93 \%$ at the end of Grade 1, whereas English-speaking children reach the same level of accuracy only in Grade 4. Similar results were reported by Seymour et al. (2003) who examined the reading development of first grade children in English as compared to 13 other European languages. They found that reading accuracy was greater than $90 \%$ in both word and nonword reading for the majority of transparent orthographic systems (e.g., Dutch, Finnish, German, Greek, Italian, and Spanish). In contrast, children learning to read in orthographically less transparent languages such as Danish and Portuguese showed low levels of accuracy on nonword reading. In particular, English children showed limited accuracy levels in both word (34\% correct) and nonword (29\% correct) reading. English children's rate of reading development was more than twice as slow as the children learning to read in consistent orthographic systems. These results suggest that reading ability takes longer to develop in less transparent orthographies.

However, regarding the effects of the transparency of a written language on which underlying skills children use to read, the findings of empirical research are inconsistent. In some studies, evidence shows that children learning to read in transparent 
orthographies show the same developmental pattern as the children learning to read in opaque orthographies. Findings from other studies, in support of the orthographic depth hypotheses, have reported that phonological skills play an essential role in reading development of transparent orthographies.

For instance, Spencer and Hanley (2003) compared the reading development of English and Welsh-speaking children and reported that the two groups differed on accuracy levels and skills used to read words and nonwords. In this study, children's error analyses showed that English-speaking children's reading errors were mostly real-word substitutions (e.g., shoe for school or no for on), whereas Welsh-speaking children showed more phonologically-based reading errors. The authors attributed these differences in children's errors to the different level of transparency between the two orthographic systems. Likewise, Sprenger-Charolles (2003) reviewed studies with beginning readers of English, French, German, and Spanish. She reported that phonological processing played a more dominant role within the reading development of French, German, and Spanish children compared to English children. English children showed less reliance on phonological processing and more reliance on non-phonological compensatory strategies such as real-word substitutions.

Goswami, Gombert, and Barrera (1998) compared reading speed and skills used by English, French, and Spanish-speaking children based on different types of nonwords. The results showed that orthographic familiarity was more important for English children and (to a lesser degree) for French children compared to Spanish children. Moreover, the length of nonwords influenced the reading speed of Spanish children, but not English and French children. These results suggest that children in less transparent orthographic 
systems are more likely to rely on orthographic skills, thus their reading speed is not affected by the length of nonwords. Children in transparent orthographies, however, use one-to-one mapping reading strategies, thus their performance is influenced by the length of nonwords. These cross-orthographic findings support the orthographic depth hypothesis which posits that the extent to which phonological skills are used to read depends on the extent to which orthographic systems represent one-to-one grapheme-tophoneme mappings.

Not all studies, however, support the orthographic depth hypothesis (e.g., Verhoeven, Bayen, \& Schreuder, 2004; Basso \& Paulin, 2003). For instance, the orthographic system of Italian is highly transparent and there are a few letters that have word-specific pronunciation (Job, Peressotti, \& Mulatti, 2006). To investigate whether Italian children pass from the use of phonological skills to orthographic skills, Job (1994) compared Grade 2 and 5 Italian children's reading performance of words and nonwords in a "homogeneous case" (CAT) or in "case alteration" (cAt). The logic behind this design was that "case alteration" should affect the use of orthographic skills which is based on orthographic units more than phonological skills which is based on single letters. The results showed that "case alteration" affected older children's reading performance more than younger children's reading. In addition, word reading was more affected than nonword reading. These results suggested that as young Italian children applied phonological skills to read, their reading performance was not affected by orthographic information. Likewise, nonword reading was not affected by orthographic changes as nonwords are, typically, read by relying on phonological skills. Similarly, Sonzogni (1989) reported that the reading performance of Italian children in low and high 
grades differed both quantitatively (accuracy level) and qualitatively (skills used to read). In this study, while $62 \%$ of Grade 5 children relied on orthographic skills to read words, only $3 \%$ of Grade 2 used orthographic knowledge (cited in Job et al., 2006). Taken together, these results suggest that both phonological and orthographic skills are applied to reading a transparent orthography such as Italian. Phonological skills are most important early in young Italian children's reading, whereas orthographic skills become relevant in older children's reading performance.

The pattern of reading development reported in transparent orthographies is similar to that obtained from studies in English, an opaque orthographic system. For instance, Aaron et al. (1999) compared English-speaking children and adults' latencies on word and letter naming. The results showed that English-speaking children from Grade 2 took a longer time to name a list of monosyllabic common words than to read a list of letters. However, children from Grade 3 and on, including college students, read both letters and words at the same rate or named words at a faster rate than letters. Thus, since young children rely on decoding procedures, the length of the stimuli affects their reading latencies, but skilled readers' performance is not influenced by the length of stimuli due to reliance on orthographic skills.

Likewise, Waters, Seidenberg, and Bruck (1984) studied the effects of regularity on word reading among English-speaking third and fifth graders together with university undergraduates. They reported that Grade 3 children showed greater regularity effects than Grade 5 children and skilled readers. That is, Grade 3 children read irregular words slowly and less accurately than regular words. The authors attributed the difference between young and older participant to the participants' orthographic skills. In this study, 
young children probably relied on phonological skills; therefore they read irregular words slowly and less accurately than regular words. However, this was not the case for older children and adults, as they were more likely to have a larger lexical memory of the words and read them by relying on orthographic skills. Taken together, the results of these studies support the notion that young children are more sensitive to the inconsistencies of orthography than older children, suggesting that young children rely on phonological skills more than older children.

The effect of orthographic depth on children's rate of reading development and skills used to read can be measured precisely within an orthography. In the present study, Persian children's reading accuracy and latencies on transparent and opaque words were compared to examine the effect of Persian transparency on reading development over time.

\section{Skills Used to Spell}

Compared to research on children's reading development, children's spelling has not been studied extensively. In addition, no comprehensive longitudinal study of spelling development has been published that examines learners of languages other than English. Moreover, the limited research has not focused on the validity of the orthographic depth hypothesis in terms of skills used to spell.

Nonetheless, there are some cross-orthographic studies showing that children learning to spell in consistent orthographies such as Czech (Caravolas \& Bruck, 1993), or German (Wimmer \& Landerl, 1997) show faster rate of spelling development than English children. In particular, findings from within orthographic studies reveal that it is easier to spell a word when each phoneme consistently corresponds to a simple grapheme 
(Juul, 2005; Rahbari Sénéchal, \& Arab-Moghaddam, 2007). Recently, Juul (2005) examined Danish-speaking children's spelling accuracy based on different levels of orthographic consistency. There were three types of words; (a) words with phonemically single plausible spellings that had only one possible spelling at the phonemic level, (b) words with context sensitive spellings that had two or more phonemically plausible spellings, but these phonemes occurred in contexts where one of these possible spellings is used almost exclusively, and, (c) word-specific items that had two phonemically plausible spellings where neither of the phonemes could be excluded from considerations of the phonological context. The results showed that children spelled words including single phoneme and words including context sensitive phonemes more accurately than word with specific phonemes, although the use of context sensitive spellings was significantly more difficult than use of phonemically plausible spellings. Similarly, Caravolas, Kessler, Hulme, and Snowling (2005) showed that the spelling of British children as young as 5 was influenced by consistencies of phoneme-to-grapheme correspondences. Thus, children's spelling accuracy appears to be a function of orthographic consistency.

Although cross-orthographic studies directly investigating the role of phonological and orthographic skills in spelling within orthographic systems varying in consistency are rare, other studies have provided evidence showing that the use of phonological skills is more dominant than orthographic skills when spelling consistent orthographies. For instance, Turkish orthography is characterized by entirely transparent bidirectional mappings between phonology and orthography (Raman \& Weekes, 2005). Oney and Durgunoglu (1997) examined Grade 1 Turkish children's spelling performance 
three times during the year on the same set of words and nonwords. They reported that phonological skills were a significant predictor of word and nonword spelling among Turkish children. Similar results were reported in Italian, a transparent orthography. Tressoldi (1996) reported that there was no significant difference in error rates of words and nonwords spelling for Italian children from Grade 2 to 8 and that the decrease in error rate from Grade 2 to 8 was very low. Tressoldi attributed these results to the important role of phonological skills in Italian children's spelling. The spelling results obtained from both Turkish and Italian children suggest that these children applied the same skill to spell both words and nonwords. This skill was the use of phoneme-tographeme conversion rules.

Another way to determine the relative use of phonological and orthographic skills in children's spelling is based on the types of spelling errors. The analyses of Germanspeaking children's spelling errors showed that the majority of German-speaking children's errors were phonological errors. However, the pattern of errors among their English counterparts obtained from other studies (e.g., Seymour \& Elder, 1986; Stuart \& Coltheart, 1988) showed that when English-speaking children did not know the spelling of the words, they either substituted already known words that were visually similar to the target words or they refused to answer (Wimmer \& Hummer, 1990). The pattern of errors observed show that German-speaking children relied on small units, namely, phoneme-grapheme correspondence rules to spell words from the beginning, whereas English children used visual cues.

The pattern of skills used in Turkish-, Italian- and German-speaking children's spelling, however, differ from that of less consistent orthographic systems such as 
English. For instance, Juel, Griffith and Gough (1986) reported that both phonological and orthographic skills accounted for a statistically significant portion of variance in the spelling of English-speaking first and second graders. Juel et al. (1986) argued that although both phonological and orthographic skills play an essential role in learning to spell, in orthographically inconsistent languages such as English with limited one-to-one phoneme-to-grapheme correspondences, orthographic skills dominate very quickly from the beginning of literacy acquisition.

There is other evidence showing that orthographic skills play an important role in English-speaking children's spelling from the beginning (e.g., Treiman, 1993; Treiman et al., 1994; Varnhagen, MCcallum, \& Burstow, 1997). For instance, Treiman et al. (1994) found that young English children were able to use simple morphological information in their spelling. Bruck and Waters (1990) showed that although there are developmental and individual differences in the use of different types of skills in English-speaking children's spelling performance, all children were able to use different linguistic information in words in their spelling. Similarly, in their overlapping waves hypothesis, Rittle-Johnson and Siegler (1999) have argued that English-speaking children may rely on various skills (e.g., analogous spelling) early in their spelling. These findings may suggest that English-speaking children rely on different skills to spell since the one-toone phoneme-to-grapheme correspondences in English orthographic system are not typically reliable. However, more studies on spelling development in other orthographic systems are needed to compare the pattern of skills used to spell in different orthographic systems. 
Although the findings for spelling reviewed so far reveal no reliable pattern of skills used to spell in consistent versus inconsistent orthographies, it may be inferred that children rely on phonological skills to spell words when one-to-one phoneme-grapheme conversion rules are available but may also apply other skills such as orthographic skills when these correspondences are not reliable. In the present study, Persian children were required to spell words that differed in consistency levels to examine the effect of Persian spelling consistencies on children's spelling accuracy and the skills used to spell words.

\section{The Characteristics of the Persian Orthographic System}

The Persian language has 23 consonant sounds and six vowel sounds. The articulation of Persian consonant or vowel sounds may be changed depending on their position in a word. For instance, the sounds $/ \mathrm{p}, \mathrm{t}, \mathrm{k} /$ are strongly aspirated in word-initial position than in other positions (Majidi \& Ternes ,1999). The Persian vowels are generally known as either long, /p:/ /i://u:/, or short, /æ/ /e//o/, in length. However, it is argued that the length of vowels is not distinctive, all Persian vowel sounds are rather long in a stressed position. The vowel sounds $/ \mathfrak{x}, \mathrm{e}, \mathrm{o} /$ are long or half-long before consonant clusters. Moreover, all vowels sounds are nasalized before or after the nasal consonants $/ \mathrm{m} /, \mathrm{n}$ / (Majidi \& Ternes ,1999). Word-final /o/ does not occur frequently, and word-final /æ/ is very rare in Iranian Persian. Although there may be other regularities in the articulation of Persian vowel or consonant sounds, for the purpose of this research we will use the classification of long and short vowel sounds because it corresponds with the presence or absence of vowel graphemes in Persian orthography.

The Persian orthography consists of 32 alphabetic letters that are written from right to left. While most letters consist of distinct symbols, there are some letters for 
which the distinguishing features are dots and other diacritics. Although there are no upper cases or lower cases in Persian letters, there are many letters that have different shape depending on their position in the word and whether or not they should be written connected to another letter. Persian alphabetic letters together with their names and sounds are represented in Appendix C. The Persian orthography is usually viewed as having consistent letter-sound correspondence rules because each grapheme has a single pronunciation (Baluch, 1993; Baluch \& Besner, 1991), but Persian is not entirely transparent. That is, only the three long vowels of Persian are represented by letters, whereas the three short vowels are not represented by letters or diacritics after the first year of reading instruction. Hence, words, or syllables within words, that have short vowels are spelled as a sequence of consonants. Given this characteristic, it is possible that the same sequence of consonants represents three different words. For example, the Persian word srd could be pronounced /særd/, /sord/, /serd/, but, in this case, only the first pronunciation corresponds to a real word meaning cold. Hence, obtaining the correct pronunciation of these words requires reliance on semantic knowledge. Persian short vowel selection is represented in Figure 1. The Persian words for which all phonemes are represented with letters are transparent words and the words that include short vowels that are not represented by letters are opaque words. These characteristics of Persian allowed us to examine whether the level of orthographic transparency of words, namely, the presence or absence of a letter to mark a vowel, would affect reading performance. Previous research with Persian children has shown that the Persian transparency does affect reading (Baluch \& Shahidi, 1991). 
Another key characteristic of the Persian orthography is the relative inconsistency of the sound-letter correspondence rules. In Persian, there are six phonemes that can be marked by more than one letter. Specifically, the phoneme / $z$ / can be represented by four

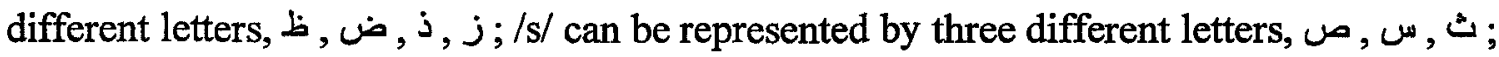
/t/ by two different letters, $b, \Xi ; / h /$ by two letters, $\tau, \circ ; /$ / by two letters, $\varepsilon, 1$; and /G/ by two letters , ق,$\dot{\varepsilon}$. Obtaining the correct spelling of words that contain these polygraphic letters requires reliance on orthographic skills. In the present study, polygraphic words are those for which more than one letter can represent the same phoneme, whereas nonpolygraphic words have no alternative spelling and each phoneme corresponds with a single grapheme. Previous research with children has shown that polygraphy does not affect reading accuracy, but does affect spelling accuracy (Rahbari Sénéchal, \& Arab-Moghadam, 2007). Figure 2 represents a correct selection of a polygraphic letter in a polygraphic Persian word. 


\section{Figure 1}

Short Vowel Selection in Persian Opaque Words

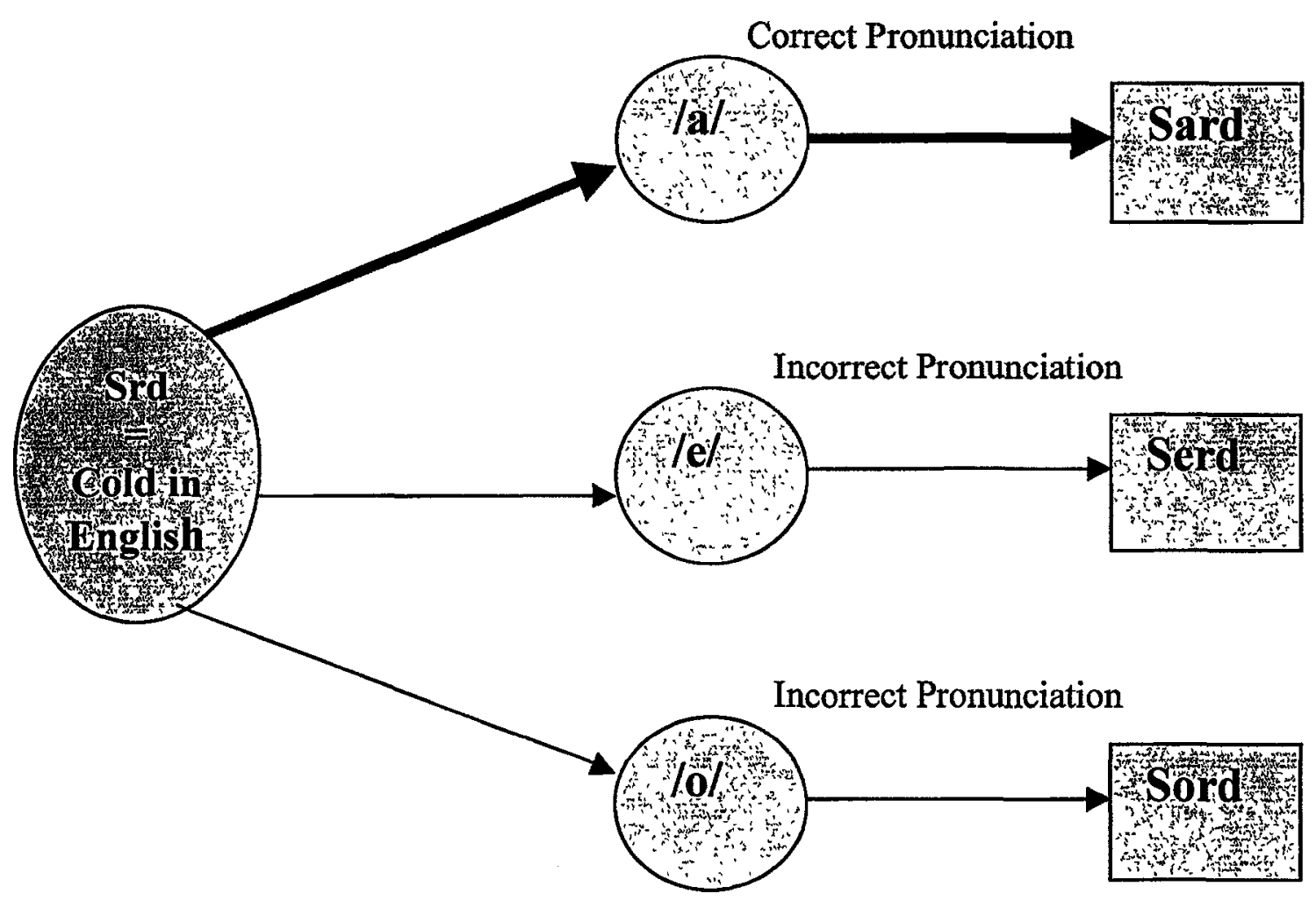


Figure 2

Polygraphic Letters Selection in Persian Polygraphic Words

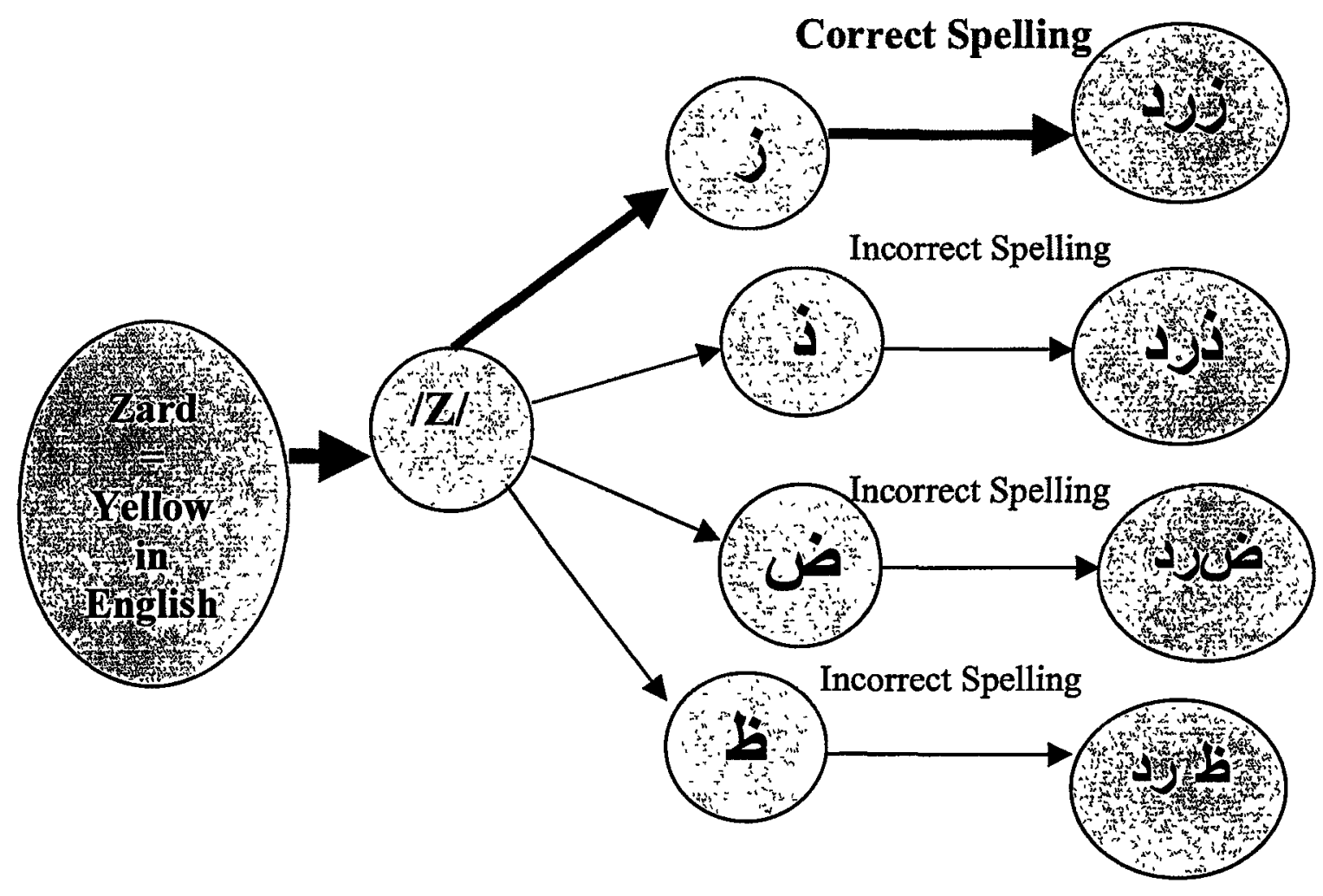




\section{Reading and Spelling in Persian}

There are a few studies that have addressed the role of phonological and orthographic skills in Persian children's reading and spelling (Arab-Moghaddam \& Sénéchal, 2001; Rahbari, Sénéchal, \& Arab-Moghaddam, 2007) and in Persian adults' words recognition (e.g., Baluch, 1993; Baluch \& Besner, 1991; Baluch \& Besner, 2001; Rahbari \& Sénéchal, 2008).

Rahbari et al. (2007) examined the relative contribution of orthographic and phonological skills to monolingual Persian Grade 2 children's reading and spelling. The results of regression analyses revealed that the unique contribution of phonological skills (18\% and $17 \%$ for reading and spelling, respectively) was substantially higher than that of orthographic skills ( $3 \%$ and $6 \%$ for reading and spelling, respectively). Note that in this study children's phonological skills were assessed with a pseudoword reading test and their orthographic skills were assessed by a forced-choice task that contained a pair of words including a real word and a pseudohomophone of that word. Furthermore, the results showed that spelling accuracy depended on the levels of inconsistency of the stimuli. Persian children spelled nonpolygraphic words more accurately than polygraphic words ( $84 \%$ versus $49 \%)$. These results revealed that inconsistencies of Persian orthography in terms of phoneme-grapheme correspondences affect children's spelling performance. However, in Rahbari et al. (2007) the stimuli were matched only on spelling consistency polygraphy (i.e., polygraphic vs. nonpolygraphic words) but not based on reading transparency. More than $90 \%$ of words in this study were opaque words. Moreover, the participants were only Grade 2 Persian children, therefore developmental patterns of skills used to read and spell are not evident in this study. 
Baluch and Shahidi (1991) examined Persian children's (mean age 8.4 years) performance on transparent and opaque word reading. Although the sample size in Baluch and Shahidi (1991) was very small and children were from different grade levels, results suggested that children read opaque words significantly less accurately than transparent words. Moreover, the time taken to name a list of opaque words was significantly slower than the time to name a list of transparent words. Baluch and Shahidi attributed these results to the dominant role of phonological skills in young Persian children's reading as their performance was affected by the transparency of Persian.

The effect of orthographic transparency on reading has also been examined with bilingual children who concurrently learn to read in Persian, as a first language, and English as a second language. If the transparency of an orthography affects children's reading, bilingual Persian-English children should read Persian words more accurately than matched English words because Persian orthography has more reliable one-to-one grapheme-phoneme correspondence compared to the English orthographic system (ArabMoghaddam \& Sénéchal, 2001; Gholamain \& Geva, 1999). For instance, Gholamain and Geva (1999) compared the linguistic, cognitive and reading skills of 70 bilingual PersianEnglish children's performance from Grade 1 to 5 in English and Persian. They reported that with only 3 hours of Persian literacy instruction per week, children who had mastered decoding rules were able to read unfamiliar Persian words in the early grades more accurately than English words. The authors attributed these results to the relatively higher transparency of the Persian orthography in comparison to the English orthographic system. 
Although findings with Persian monolingual children reveal that phonological skills are important in Persian reading, studies with Persian adults have shown that orthographic skills play a dominant role in the skilled reading of Persian (e.g., Baluch, 1993; Baluch \& Besner 1991; Rahbari \& Sénéchal, 2008). For instance, Baluch (1993) examined the effects of transparency on the reading latencies of Persian adults. The results revealed that the latencies for high-frequency words were equally fast for both transparent and opaque words. However, latencies of lower-frequency transparent words were faster than the matched opaque words. The observed interaction between word frequency and transparency effects in this study showed orthographic processing is dominant in the skilled reading of Persian. Similarly, Nassaji and Geva (1999) reported that the unique contribution of orthographic processing was more pronounced than phonological processing in Persian adults' reading.

Rahbari and Sénéchal (2008) examined 61 monolingual Persian senior highschool students' reading and spelling of words and nonwords. The word stimuli were either transparent or opaque in terms of reading and nonpolygraphic or polygraphic words in terms of spelling. The nonwords were transparent and nonpolygraphic. In this study, lexicality effects were used as an index to measure the reliance on phonological skills. The reading results showed strong lexicality effects for both Persian transparent and opaque words, that is, both transparent and opaque words were read faster than nonwords. These findings suggest that skilled readers of Persian relied on orthographic skills to read words. In contrast, the spelling results showed no lexicality effects either for nonpolygraphic or polygraphic words. In this study, nonpolygraphic words were spelled as fast as nonwords; in addition, polygraphic words were spelled less accurately and more 
slowly than nonwords. This suggests skilled Persian spellers relied on nonlexical processes to spell words.

Taken together, the findings from the studies reviewed above suggest that phonological skills play a dominant role in Persian children's reading, but orthographic skills are salient in Persian adults' word naming. The extant research, however, is limited because it does not represent the developmental pattern of skills used to read transparent and opaque words separately. The present study compared children's performance on word and nonword reading to measure the contribution of phonological and orthographic skills to Persian transparent and opaque word reading over time. The limited findings regarding Persian spelling suggest that phonological skills are important both in Persian children's and adults' spelling. To study the developmental patterns of skills used to spell Persian, children's spelling accuracy and speed were tested for polygraphic and nonpolygraphic words as well as for nonwords. 


\section{Associations between Reading and Spelling}

\section{Introduction: Nature and Direction of the Relation}

Reading and spelling are related abilities and it seems skills in one ability automatically transfer to the other. Individuals with reading and spelling abilities are able to convert printed words into associated sounds in order to read words as well as convert spoken words to print when spelling words (Coenen, Van Bon, \& Schreuder, 1997). Studies have shown a strong positive correlation between children's reading and spelling performance. Malmquist (1958) reviewed several studies and reported correlation coefficients ranging from .50 to .80 . Likewise, in reviewing recent empirical research, Ehri (2000) reported correlation coefficients ranging from .68 to .86 , which are similar to those reported by Malmquist.

Regarding the direction of the relationship between reading and spelling, three hypotheses have been examined in the literature; (a) early reading predicts later spelling achievement (Francies, 1994; Juel, 1988); (b) proficiency in early spelling predicts achievement in reading (Caravolas, Hulme \& Snowling, 2001); and, (c) the relation between reading and spelling is reciprocal (e.g., Fitzgerald \& Shanahan, 2000; Lerkkanene, Rasku-Puttonen, Aunola \& Nurmi, 2004, Leppanen, Niemi, Aunola \& Nurmi, 2006; Foorman, Francis, Novy, Liberman 1991; Shanahan \& Lomax, 1986).

In a longitudinal study with English-speaking children, Juel (1988) showed that poor readers in Grade 1 tended to remain poor readers and writers at the end of Grade 4. Writing ability did not predict later reading and writing abilities in this study which supports the first hypothesis that early reading predicts later spelling ability. Some support is available for the second hypothesis proposing that spelling predicts later 
reading in the early years of education. For example, in a three year longitudinal study, Caravolas and colleagues (2001) reported that phonological spelling (i.e., preconventional stage of spelling) was a strong predictor of later reading $(r=.70)$. However, reading did not predict phonological spelling of English-speaking children at any time during of testing. Reading ability in third year of schooling was a strong predictor of conventional spelling $(r=.73)$.

In contrast to the first two hypotheses regarding the association between reading and spelling, the third hypothesis proposes bidirectional relations between reading and spelling. This hypothesis has gained relatively more support than the others from research conducted in multiple languages. For instance, in a year-long investigation of Grade 1 English-speaking children's reading and spelling abilities, it was shown that early reading ability was associated with faster growth in later spelling while more accurate spelling was predictive of later reading. Moreover, greater phonological skill was predictive of the accuracy level of both reading and spelling (Foorman, et al., 1991).

The bidirectional relationship between reading and spelling is also supported by evidence obtained from other languages (e.g., Lerkkanene et al., 2004; Leppanen et al., 2006). For instance, Lerkkanen et al. (2004) tested reading and spelling of Finnishspeaking children four times in first grade to determine the relations between reading and spelling performance in the beginning of literacy development. The results showed that reading and spelling manifested a reciprocal relationship during the first semester of Grade 1, however, later on, reading predicted spelling in a less reciprocal association.

Given that there is a positive and strong correlation between reading and spelling when measured at the same time, it is reasonable to expect that reading and spelling show 
the same accuracy level. However, not all researchers who have studied reading and spelling together agree with this statement. Although the relation between reading and spelling accuracy has not been investigated directly, some researchers have claimed that spelling is harder than reading. The next section will discuss the potential factor(s) that may create a discrepancy between reading and spelling accuracy in some orthographic systems.

\section{Is Spelling Harder than Reading?}

It is generally thought that spelling is more difficult than reading as the former involves recalling and producing a word whereas the latter involves simple recognition. In some languages studies jointly investigating reading and spelling development have represented evidence that supports this notion (e.g., in English, Bruck \& Waters, 1988; Stage \& Wagner, 1992, in French, Eme, \& Golder, 2005; Sprenger-Charolles \& Casalis, 1995; Sprenger-Charolles, Siegel, \& Bonnet, 1998; Sprenger-Charolles, Siegel, Bechennec, \& Serniclaes, 2003). These researchers have reported that children read words more accurately than they are able to accurately spell the same words. For instance, Eme and Golder (2005) recently reported French-speaking second grade children can read $73 \%$ of French words, yet can spell $46 \%$ of the same words. This pattern is, however, not the same for all languages.

In a comparison study between Italian and English-speaking children from 6- to11 years old, Thorstad (1991) reported that English-speaking children could read more words than they could spell, whereas Italian children could spell most of the words that they could read. Note that Italian and English are located in opposing dimensions of orthographic consistency (Seymour et al., 2003). Italian orthography is consistent in 
terms of both grapheme-to-phoneme and sound-to-print relation whereas English has an inconsistent orthography for both reading and spelling. Moreover, English orthography is less consistent in terms of spelling than reading, but this is not the case for Italian. These findings raise the possibility that differences in children's reading and spelling accuracy may be related to factors such as inconsistency/irregularity effects, rather than the difficulty of the task by itself.

For instance, Persian second graders performed less accurately when spelling compared to reading the same Persian words (64\% versus $72 \%$ ) when polygraphic words were included in the analysis (Rabari et al., 2007). However, when Persian children's performance was analysed only for nonpolygraphic words, performance on the spelling task ( $82 \%$ accurate) was superior to the reading task ( $74 \%$ accurate). Persian children's spelling accuracy for polygraphic words was only $46 \%$, an accuracy rate half the size of the accuracy for nonpolygraphic words. These significant findings may suggest the reading and spelling accuracy differences reported by some researchers may be related to the differences of reading and spelling consistency levels within orthographic systems.

Although a growing number of cross-orthographic comparisons have examined the effects of inconsistencies on children's performance (e.g., Defior, Martos \& Cary, 2002; Goswami, Propodas, \& Wheelwright, 1997; Seymour, et al., 2003; Thorstad, 991; Wimmer \& Goswami, 1994; Defior \& Serrano, 2005), less research has examined the effects of inconsistencies on children's performance within an orthographic system. Particularly, comparisons between the effects of inconsistencies in terms of reading and spelling within an orthographic system have not been investigated clearly and deeply in the literature of children's literacy development. 
Orthographic inconsistencies not only differ across languages, but single orthographic systems may also differ in consistency levels in terms of reading and/or spelling. For example, languages such as English, French, German, and Portuguese are orthographically more inconsistent in terms of spelling than reading (Defior et al., 2002; Ventura, Morais, Pattamadilok, \& Kolinsky, 2004; Ziegler, Jacobs, \& Stone, 1996; Ziegler, Stone, \& Jacobs, 1997). Recent statistical analyses on the English orthographic system have shown that $75 \%$ of English monosyllabic words are inconsistent in term of spelling, whereas only $31 \%$ of them are inconsistent in terms of reading. The inconsistencies of the French orthographic system are $79 \%$ for spelling, but $12 \%$ for reading ( for more information see Ziegler et al., 1996; 1997). Likewise, it is reported that inconsistencies of the German orthographic system in terms of spelling are $53 \%$ whereas for reading they are $16 \%$ (reported in Wimmer \& Mayringer, 2002). These discrepancies between consistency level of reading and spelling in some orthographic systems means that a word can be consistent in terms of reading but inconsistent in terms of spelling. Therefore, it is natural that children learning to read in these orthographic systems will perform less accurately in spelling than in reading when they are required to read and spell the same words.

There is evidence that within languages with less orthographically consistent spelling compared to reading, reading ability is developed more accurately and quickly than spelling ability (e.g., Pinheiro, 1995). For instance, Portuguese children reached orthographic representation more rapidly in reading than spelling because the Portuguese orthographic system is less consistent in terms of spelling than reading (Defior et al., 2002; Ventura et al., 2004). Moreover, reading and spelling were affected differently by 
regularity effects. While the regularity of words affected Portuguese children's reading ability only in the beginning of literacy acquisition, regularity affected spelling from Grade 1 to 4 (Pinheiro, 1995). However, differences in consistency between reading and spelling needs to be investigated more directly as the words used to detect Portuguese children's use of orthographic skills in reading and spelling involved words with mostly irregular spellings (e.g., the English word cheek is consistent for reading but is inconsistent for spelling). The lack of regularity effects in reading cannot be taken as an indicator of orthographic processes as the words could be read as regular words but spelled as irregular words. In order to compare children's reading and spelling accuracy levels, it is important to use words equal in regularity/consistency levels.

The present study compared Persian children's reading and spelling performance on words carefully matched on complexity levels for reading and spelling to evaluate the difficulty level between the two tasks. Specifically, I examined whether Persian children would show the same accuracy levels when they read and spelled words that were consistent for both reading and spelling. 
IV. The Present Study: Summary and Hypotheses

The main objective of the present study was to investigate the role of phonological and orthographic skills in Persian reading and spelling at different grade levels. Moreover, it was of interest to investigate the relative difficulty level between reading and spelling. In the present study, the index of the lexicality effect was used to assess reliance on orthographic skills. If orthographic skills are used, real words should be read and spelled faster and more accurately than nonwords because nonwords do not have an orthographic representation and, consequently, require phonological processes. Corroboration for this interpretation was obtained by examining whether both transparent and opaque word reading was correlated with word frequency. Further evidence of orthographic processing for spelling was obtained by testing whether word frequency was correlated with the spelling of polygraphic and nonpolygraphic words. Orthographic processes are sensitive to word frequency; consequently, higher frequencies should be correlated with higher accuracy and faster speed.

To assess the use of phonological skills, however, transparency effects (transparent vs. opaque words) were manipulated in a Persian reading task and polygraphy effects (polygraphic vs. nonpolygraphic words) were manipulated in a Persian spelling task, respectively. If phonological skills are used, opaque words should be read less accurately and more slowly than transparent words. Similarly, if phonological skills are used to spell, polygraphic words should be spelled less accurately and more slowly than nonpolygraphic words.

In sum, the presence of a lexicality effect without a transparency effect would indicate reliance on orthographic processes for reading Persian. Inversely, the presence of 
a transparency effect without a lexicality effect would indicate the use of phonological processing. Likewise, the presence of a lexicality effect with the lack of a polygraphy effect would indicate reliance on orthographic processes for spelling Persian. Inversely, the presence of a polygraphy effect without a lexicality effect would indicate reliance on phonological skills to spell Persian.

Developmental predictions in the present study were based on findings obtained from Persian children and adults as well as evidence from other orthographic systems. For reading, it was predicted that in the early grades phonological skills play a dominant role and that in the later grades orthographic skills become more salient. It was also predicted that transparency effects may be present in all grades with a larger effect for younger children than older children. Similarly, it was predicted that the magnitude of the lexicality effect would increase with children's grade levels. Regarding Persian spelling, it was expected that performance would increase with school experience; however, more specific hypotheses were difficult to make given the limited and inconsistent evidence currently available. If the two are analogous, one could hypothesize that the spelling results will resemble the reading results.

In order to compare the relative difficulty of reading and spelling, children's performance at different grade levels was compared on two types of words, transparentnonpolygraphic words and opaque-polygraphic words. This was done to assess whether the reported discrepancies between reading and spelling by some researchers were due to potential differences between these two abilities, or due to other factor(s) such as different orthographic inconsistencies for reading and spelling. It was anticipated that Persian children will not show significant differences in accuracy levels for reading and 
spelling when they read and spell transparent-nonpolygraphic words. However, children may read opaque-polygraphic words significantly better than they spell the same words; the limited findings from empirical research in Persian suggest that inconsistencies affect spelling performance more than reading performance (Baluch, 2006; Rahbari et al., 2007). For instance, Rahbari and Sénéchal (2008) reported that Persian skilled readers' error rates when spelling polygraphic words were three times higher than their error rates when reading opaque words ( $4.50 \%$ vs. $1.30 \%$ ). Similar results were obtained from Grade 2 Persian children's performance when spelling polygraphic words and reading opaque words. While children read $72 \%$ of opaque words accurately, they spelled $46 \%$ of polygraphic words correctly (Rahbari et al., 2007). 


\section{Method}

\section{Participants}

One hundred and forty monolingual Persian children, 76 girls and 64 boys, attending Grades 1 to 4 in Tehran, Iran participated in this study. One participant from Grade 4 was excluded because she did not complete all required tasks. Therefore, there were 35 children in Grade 1, 20 girls and 15 boys; 35 in Grade 2, 19 girls and 16 boys; and 35 in Grade 3, 19 girls and 16 boys; but 34 children in Grade 4, 18 girls and 16 boys. Children's chronological age ranged from 6 years to 10 years of age (mean age $=9 ; 02$, $S D=13$ months, range $=78$ to 124 months). That is, at the time of testing, Grade 1 children had a mean age of 84 months ( $S D=3$ months, range $=78$ to 89 months); Grade 2 children had a mean age of 96 months ( $S D=3$ months, range $=91$ to 100 months); Grade 3 children had a mean age of 107 months, $(S D=4$ months, range $=100$ to 113 months); and Grade 4 children had a mean age of 118 months ( $S D=5$ months, range $=$ 107 to 124 months). The children were recruited from three public schools (two schools for girls and one school for boys) and six classrooms for each grade.

All students had normal reading and spelling ability and had no cognitive and psychological difficulties according to their classroom teachers. Also, all children were native speakers of Persian and had normal or corrected to normal vision. Moreover, although it was not possible to match children based on their IQ scores due to unavailability of a standardized IQ test, children were matched on their academic progress across grades. All children who participated in the present study had general averages of 17 or above (out of 20) in all subjects including reading and spelling in the related grade. If a student had a general average of 17 or above in other subjects, but 
her/his grades on reading or spelling were below 17 out of 20 , he/she was not included in the study. Note that there is a formal general academic progress examination every three months in Iranian schools. Data for children in Grade 4, 3, and 2 were collected in the middle of the school year, whereas data for Grade 1 children were collected at the end of school year. Grade 1 children typically complete learning letters at the end of their first grade.

In Iran, formal schooling starts when children reach seven years of age and an education-year is completed in 9 months. Prior to formal schooling, very little formal reading takes place. Although children may attend kindergarten before school entry, the kindergarten program explicitly discourages any school-related activities such as teaching letters. Grade 1 Persian children are initially taught to read and spell using diacritics for short vowels; however, after a few months of education, children are encouraged to read and write without diacritics. In contrast to English where both letter names and sounds are taught to children, in Persian only letter sounds are formally taught to children. Unlike English where most letters have different names and sounds, the majority of letters in Persian have equivalent sounds and names or the letter names include the letter sounds. Textbooks are used to teach reading in each grade and the same series of books is used throughout the country. Although the most typical teaching approach in Iran is a phonics method, recently, some teachers use whole-word teaching methods as well.

\section{Measures}

Participants' reading and spelling abilities were tested on words (60) and nonwords (40). The word and nonword lists were the same across all grade levels and were the same for reading and spelling. For both reading and spelling tasks, latencies and 
error rates were measured. An explanation of the process of word selection and word type as well as the construction of nonwords follows.

\section{Word Stimuli}

Word type. Participants read and spelled the same 60 real words to provide an equivalent measure of reading and spelling (see Appendix A). The word types were obtained by crossing reading transparency (transparent vs. opaque) with spelling consistency (nonpolygraphic vs. polygraphic). To be clear, reading transparency included two levels: transparent words were those for which all phonemes were represented with letters whereas opaque words were those that included short-vowel phonemes that are not represented with letters. Spelling consistency also included two levels: nonpolygraphic words included phonemes with unique consistent orthographic representations whereas polygraphic words included phonemes with inconsistent (i.e., multiple) orthographic representations. This crossing of reading transparency and spelling consistency yielded 15 words that were transparent and nonpolygraphic, 15 words that were transparent and polygraphic, 15 words that were opaque and nonpolygraphic, and 15 words that were opaque and polygraphic. Thus, the 60 words included a total of 30 transparent words and 30 opaque words for analyzing reading transparency, or, for analyzing spelling consistency, 30 nonpolygraphic and 30 polygraphic words.

Word selection and characteristics. The words were selected from Persian school textbooks used from Grade 1 to 5 . All words had a single correct pronunciation, a single correct spelling, and a single meaning. That is, there were no words that could be read correctly by using different short vowels, or spelled correctly using a different grapheme 
for the same phoneme. 56 items were three-letter monosyllabic words and four items were four-letter two-syllable words. One two-syllable word was placed in each of the four Transparency X Consistency word types described in the previous section. The transparent and opaque words had the same number of letters, but had different orthographic structures. The transparent words were CVC (for one syllable words) or CVCV (for two syllable words) in structure, whereas the opaque words were either CCC (for one syllable words) or CCCC (for two syllable words) with a short vowel pronounced after the initial consonant as well as the third consonant for the words with two-syllables. Most important, the transparent and opaque words were matched on acoustic duration, frequency (see Table 1) and initial consonant onset. There were no statistically significant differences for acoustic duration or frequency when comparing transparent and opaque words as well as when comparing polygraphic and nonpolygraphic words.

Since objective word-frequency norms are not available for Persian, the procedure used to index word frequency is described in detail. First, 300 one- and two-syllable words were selected from Persian school books for Grade 1 to 5 . Second, 10 teachers judged the frequency of each item in written or spoken Persian on a 7-point scale (where 1 indicated infrequent and 7 indicated very frequent words). This method of wordfrequency assessment has been previously used by other researchers (e.g., Baluch \& Besner, 2001; Ziegler, Ferrand, \& Montant, 2004). The resulting frequency for each word was averaged across teachers. Third, items rated at the end points of the rating scales (i.e., 1 or 7) were excluded to ensure that items were not too familiar or too rare. Fourth, words in each category were matched as closely as possible on frequency level. Finally, in order 
to ensure that the selected words were within the spoken vocabularies of Grade 1 children, three Grade 1 teachers were asked to verify the familiarity of words for Grade 1 children. If a word was identified as unfamiliar to Grade 1 children, it was replaced with a familiar word and the evaluation was repeated. The averaged frequencies and acoustic durations are reported for each word in Appendix A and across word types in Table 1.

Nonword Stimuli

Children read and spelled the same 40 nonwords. All nonwords were transparent in terms of reading and nonpolygraphic in terms of spelling. That is, all nonwords had long vowels and none included short vowels or polygraphic phonemes. Also, nonwords were decodable and had a legal orthography (see Appendix B). The nonwords had the same orthographic structure as the transparent words, that is, 36 were $\mathrm{CVC}$, and 4 were CVCV.

The construction and selection of nonwords was as follows. First, nonwords were constructed from real words by changing the initial and/or the final consonant or by replacing a long vowel with another long vowel. The goal was for the nonwords to have little resemblance to real Persian words in order to force participants to rely on phonological skills rather than an analogy strategy to read and spell them. The list of nonwords was then examined by three educated native speakers of Persian to assess their resemblance to Persian real words. If a nonword was identified as similar to a real word in Farsi or any other minority language in Iran, it was replaced and the evaluation repeated.

Accurate reading performance for nonwords was determined when a participant decoded all the letters into their corresponding sounds correctly and accurate spelling 
performance was granted when a participant wrote the sequence of letters that captured the phonology of a nonword.

\section{Procedure and Apparatus}

Participants were tested individually in a quiet room in their schools. The reading tasks were administered at least one week before the spelling tasks to prevent any visual or auditory residual effects. Likewise, the word list was presented before the nonword list for both reading and spelling to prevent participants from extending their use of decoding procedures to reading and spelling real words (Baluch \& Besner, 1991). There was a five to ten minute pause between the presentation of words and nonwords for Grade 2, 3 and 4 children in both reading and spelling tasks, but Grade 1 children performed all tasks (reading words, reading nonwords, spelling words, spelling nonwords) in separate sessions.

The presentation order of the 60 words was random since studies have shown that blocking stimuli by type might induce the use of certain skills or processes (e.g., Kinoshita et al., 2004, Raman, Baluch \& Besner, 2004). Moreover, the random presentation of transparent and opaque words is closer to an ordinary reading situation because the Persian orthography typically contains a mixture of transparent and opaque words.

Both reading and spelling tasks were administered on a computer using the SuperLab program, version 4.0. For reading, all stimuli were presented in 24 point fontsize Persian letters on the center of the computer screen. A visual ready signal, a + sign, was presented at the center of the computer screen for $500 \mathrm{~ms}$ followed by an item which remained on the screen until a participant read the item. The experimental sessions began 
by the presentation of practice items, either six words or six nonwords, to familiarize the participants with the procedures for each task. Participants were instructed to read aloud each item that appeared on the monitor as quickly and correctly as possible. A timer began recording the reading latencies when the stimulus appeared on the monitor and ending when experimenter pressed either a yes or a no button to indicate correct or incorrect responses, respectively. Therefore, correct and incorrect responses were also recorded. The experimenter was trained to not look at the computer screen, but to listen carefully to a participant and press the yes or no button as soon as the participant responded.

Audio-recordings of the words were presented via the computer for the spelling tasks. Each participant and the experimenter heard, at the same time, the auditory stimulus through headphones. Participants were asked to write down the stimulus on a sheet of paper as fast and as correctly as possible after hearing the stimulus. There were six practice items for the word and the nonword tasks. The computer program was set up to record the spelling latencies between the auditory presentation of the stimuli until the experimenter pressed a keyboard key to stop the timer to indicate that the participant started writing the target stimulus. When the participant finished writing an item, the experimenter pressed another key on the keyboard to present the next auditory stimulus.

For nonwords, participants were told that the stimuli were nonsense words and that they should read or spell them as fast and as correctly as possible. 


\section{Table 1}

Mean (and Standard Deviation) Frequency and Duration (in milliseconds) of Words as a Function of Reading Transparency and Spelling Consistency

\begin{tabular}{lllllll}
\hline & \multicolumn{2}{c}{ Reading Transparency } & & \multicolumn{2}{c}{ Spelling Consistency } \\
\cline { 2 - 3 } \cline { 5 - 6 } & Transparent & Opaque & & $\begin{array}{c}\text { Non- } \\
\text { Polygraphic }\end{array}$ & Polygraphic \\
\hline Frequency $^{\mathrm{a}}$ & $3.48(0.89)$ & $3.51(0.67)$ & & $3.48(.92)$ & $3.29(0.61)$ \\
Duration & $731(0.09)$ & $737(0.09)$ & & $738(0.09)$ & $730(0.08)$ \\
\hline
\end{tabular}

${ }^{\mathrm{a} O n}$ a 7-point rating scale where 1 is rare and 7 frequent. 
VI. Results

Preliminary analyses verified the accuracy of data entry and potential outliers. All reading and spelling latencies were within three standard deviations from the participant and the item means. Moreover, a significant correlation coefficient between latencies and error rates verified that there was no tradeoff between speed and accuracy, $r=.71$ and $.68, p<.0001$ for reading and for spelling, respectively.

Analyses of variance using participants $\left(F_{1}\right)$ and items $\left(F_{2}\right)$ as the unit of analysis were performed separately for reading and spelling. These analyses were performed both on latencies and errors rates. Latency analyses were based on correct mean latencies. That is, responses for mispronunciations (6\%) or misspellings (10\%) were excluded in the latency analyses. In addition, the association between word frequency and latencies was examined to provide support for variance analyses. As it is the case in the extant literature, it is assumed that orthographic processes are sensitive to the frequency of each word whereas phonological processes are not. Parallel analyses were conducted for reading and spelling. Note that through out the results section, $p_{, s}<.0001$ unless otherwise indicated.

\section{Reading Performance}

The importance of phonological and orthographic skills in Persian transparent and opaque word reading was examined by index of lexicality and transparency effects. Mean latencies, standard deviations, and error rates for reading transparent words, opaque words as well as nonwords are presented in Table 2. 


\section{Table 2}

Mean Correct Latencies in Milliseconds (Standard Deviations) and Mean Percentages of Error Rates for Transparent Word, Opaque Word and Nonword Reading for Grades 1-4.

\begin{tabular}{lcccccc}
\hline \multirow{2}{*}{ Grade } & \multicolumn{3}{c}{ Reaction Time } & \multicolumn{3}{c}{$\%$ Error } \\
\cline { 2 - 7 } & Non-word & Transparent & Opaque & Non-word & Transparent & Opaque \\
\hline 1 & 1827 & 1863 & 3069 & 5.29 & 1.62 & 24.48 \\
& $(323)$ & $(387)$ & $(557)$ & $(4.91)$ & $(3.10)$ & $(11.14)$ \\
2 & 1608 & 1468 & 2098 & 1.71 & 1.05 & 15.52 \\
& $(229)$ & $(251)$ & $(494)$ & $(2.70)$ & $(1.77)$ & $(10.30)$ \\
3 & 1425 & 1252 & 1714 & 0.21 & 0.38 & 13.25 \\
& $(238)$ & $(209)$ & $(349)$ & $(0.93)$ & $(1.35)$ & $(9.51)$ \\
4 & 1321 & 1066 & 1354 & 0.22 & 0.29 & 5.20 \\
& $(185)$ & $(158)$ & $(223)$ & $(0.95)$ & $(1.72)$ & $(4.36)$ \\
& & & & & & \\
\hline
\end{tabular}


To analyse children's reading performance, a 4 × 3 Mixed Factor ANOVA was conducted with grade ( 4 levels: Grade 1 to 4 ) as between-subject factor and stimuli (3 levels: transparent word, opaque word, and nonword) as a within-subject factor on latencies and error rates separately. The results of the latency analyses are presented first followed by the results of error analyses.

Analyses of latencies. The analyses revealed a significant main effect of grade, $\mathrm{F}_{1}$ $(3,135)=75.66, \mathrm{MS}_{\mathrm{e}}=86210.44 ; \mathrm{F}_{2}(3,97)=619.41, \mathrm{MS}_{\mathrm{e}}=30613.23$, showing that older children read faster than younger children. Trend analyses were performed to understand the developmental patterns in children's reading speed across grades. The results showed that both linear and quadratic differences among grades were significant, $d=733$ for linear differences and $d=156, p<.01$ for quadratic differences. These results revealed that children read both words and nonwords faster as the grades progressed, although the differences were larger between Grade 1 and 2 children than between Grade 3 and 4 children, $M_{s}=2253,1725,1464$, and 1247 for Grades 1 to 4 , respectively.

There was also a significant main effect of stimuli, $F_{1}(2,135)=571.76, \mathrm{MS}_{\mathrm{e}}=$ 28315.20; $F_{2}(2,97)=86.21, \mathrm{MS}_{\mathrm{e}}=183631.46$. These results revealed that children's reading speed differed based on the stimuli, whether transparent words, nonwords, or opaque words. Two planned contrasts were used to test for lexicality and transparency effects. The first contrast compared transparent words with nonwords to determine the lexicality effects for transparent words whereas the second contrast compared transparent words with opaque words to measure transparency effects. The results of the first contrast showed the presence of a lexicality effect for transparent words. That is, 
transparent words $(M=1415)$ were read significantly faster than nonwords $(M=1547)$, $F_{1}(1,135)=128.99, \mathrm{MS}_{\mathrm{e}}=19090.54 ; F_{2}(1,68)=16.09, \mathrm{MS}_{\mathrm{e}}=76784.54$. These results revealed orthographic skills play a dominant role in transparent word reading. Note that lexicalization had not occurred for opaque words because opaque words $(M=2169)$ were read more slowly than nonwords. The results of the second contrast revealed a strong transparency effect, that is, transparent words were read significantly faster than opaque words, $F_{1}(1,135)=943.81, \mathrm{MS}_{\mathrm{e}}=61520.91 ; F_{2}(1,58)=107.25, \mathrm{MS}_{\mathrm{e}}=257057.91$. These results suggest that phonological skills play a dominant role in Persian opaque word reading.

The key analyses in the present study, however, are the interactions revealing the pattern of reading development over time. There was an overall significant interaction between Grade and stimuli (3 levels: transparent words, opaque words, and nonwords), $F_{1}(6,135)=90.76, \mathrm{MS}_{\mathrm{e}}=28315.20 ; F_{2}(6,97)=86.74, \mathrm{MS}_{\mathrm{e}}=30613.23$. These results suggested that children's reading speed differed based on stimuli types across the grades.

To determine at which grade level lexicality effects appeared or up to which grade level transparency effects persisted, lexicality and transparency effects were examined within each grade. The results revealed that Grade 2 children onward read transparent words significantly faster than nonwords, $F_{1}(1,34)=37.80, \mathrm{MS}_{\mathrm{e}}=9156.95 ; F_{2}(1,68)=$ 9.66, $\mathrm{MS}_{\mathrm{e}}=34765.48, p<.01$ for Grade $2, F_{1}(1,34)=65.84, \mathrm{MS}_{\mathrm{e}}=7958.64 ; F_{2}(1,68)$ $=32.17, \mathrm{MS}_{\mathrm{e}}=16157.68$ for Grade 3 , and $F_{1}(1,33)=191.33, \mathrm{MS}_{\mathrm{e}}=5778.62 ; F_{2}(1,68)$ $=90.10, \mathrm{MS}_{\mathrm{e}}=12448.84$ for Grade 4. Children in Grade 1, read transparent words as fast as nonwords, $F_{1,2}<1$. These results revealed that lexicality effects appear in Persian transparent word reading from Grade 2 onward. In particular, examination of the effect 
sizes as well as the differences between transparent word and nonword reading revealed that the size of lexicality effects increased as the grades progressed, $\eta^{2}=.04 ; d=36 \mathrm{~ms}$ for Grade $1, \eta^{2}=.53 ; d=139 \mathrm{~ms}$ for Grade $2, \eta^{2}=.65 ; d=173 \mathrm{~ms}$ for Grade 3 , and $\eta^{2}=$ $.86 ; d=256 \mathrm{~ms}$ for Grade 4 . These results revealed that children's lexical memory for transparent words improved as the grades progressed.

The comparison between opaque words and nonwords within each grade revealed that children, except those in grade 4, read opaque words slower than nonwords, $F_{1}(1$, $34)=375.71, \mathrm{MS}_{\mathrm{e}}=71816.09 ; F_{2}(1,68)=197.53, \mathrm{MS}_{\mathrm{e}}=148343.54$ for grade $1, F_{1}(1$, $34)=65.03, \mathrm{MS}_{\mathrm{e}}=64486.35 ; F_{2}(1,68)=44.58, \mathrm{MS}_{\mathrm{e}}=100791.76$, for grade 2 , and $F_{1}$ $(1,34)=55.80, \mathrm{MS}_{\mathrm{e}}=26084.54 ; F_{2}(1,68)=28.83, \mathrm{MS}_{\mathrm{e}}=57749.35$ for grade 3 Children in Grade 4 read opaque words as fast as nonwords, $F_{1,2}<1$. These results revealed the lack of lexicality effects for opaque word reading across the grades. Although opaque words were never read faster or more accurately than nonwords, the differences between opaque word and nonword reading and the size of the effects tended to decrease as the grades progressed, $\eta 2=.92 ; d=1242 \mathrm{~ms}$ for Grade $1, \eta 2=.67 ; d=$ $489 \mathrm{~ms}$ for Grade $2, \eta 2=.61 ; \mathrm{d}=288 \mathrm{~ms}$ for Grade 3 , and $\eta 2=.04 ; d=33 \mathrm{~ms}$ for Grade 4. These results may suggest the gradually increasing involvement of orthographic skills in opaque word reading.

To evaluate transparency effects over time, opaque word reading was compared with transparent word reading within each grade. There was a significant transparency effect for each grade, that is, in all grades transparent words were read significantly faster than opaque words, $F_{1}(1,34)=482.36, \mathrm{MS}_{\mathrm{e}}=52719.90 ; F_{2}(1,58)=142.84, \mathrm{MS}_{\mathrm{e}}=$ 169614.95 , for grade $1, F_{1}(1,34)=167.96, \mathrm{MS}_{\mathrm{e}}=41373.14 ; F_{2}(1,58)=52.92, \mathrm{MS}_{\mathrm{e}}=$ 
120475.49 , for grade $2, F_{1}(1,34)=184.05, \mathrm{MS}_{\mathrm{e}}=20244.86 ; F_{2}(1,58)=53.55, \mathrm{MS}_{\mathrm{e}}=$ 66089.08 , for grade $3, F_{1}(1,33)=175.10, \mathrm{MS}_{\mathrm{e}}=8035.55 ; F_{2}(1,58)=34.67, \mathrm{MS}_{\mathrm{e}}=$ 39677.31 , for grade 4 .

Although there was a strong transparency effect in all grades, the size of the effect and magnitude of the differences between transparent and opaque words decreased as the grades progressed, $\eta 2=.93 ; d=1206 \mathrm{~ms}$ for Grade $1, \eta 2=.83 ; d=630 \mathrm{~ms}$ for Grade $2, \eta 2=.81 ; d=462 \mathrm{~ms}$ for Grade 3 , and $\eta 2=.70 ; d=288 \mathrm{~ms}$ for Grade 4 . These reductions in the size of transparency effects over time again may suggest some involvement of orthographic skills in opaque word reading.

Analyses of error rates. The results for the error analyses were similar to those obtained from latency analyses. There was a significant effect of grade on error rates, $F_{1}$ $(3,135)=31.11, \mathrm{MS}_{\mathrm{e}}=14.24 ; \mathrm{F}_{2}(3,97)=39.19, \mathrm{MS}_{\mathrm{e}}=32.07$, with older children making fewer errors than younger children. A significant linear difference, $d=6 \%$, across grades revealed that children made fewer errors as they progressed through the school experience, $M_{s}=11 \%, 6 \%, 5 \%$, and $2 \%$, for Grades 1 to 4 , respectively.

There was also a significant main effect of stimuli (3 levels: transparent words, opaque words, and nonwords), $F_{1}(2,135)=297.22, \mathrm{MS}_{\mathrm{e}}=27.53 ; F_{2}(2,97)=41.34$, $\mathrm{MS}_{\mathrm{e}}=177.59$. These results revealed that children's reading accuracy differed based on word types, $M_{s}=1 \%, 2 \%$, and $15 \%$ for transparent words, nonwords, and opaque words, respectively. To measure lexicality and transparency effects, two planed contrasts were used. The first contrast compared children's accuracy on transparent words versus nonwords to determine the presence of lexicality effects whereas the second contrast compared transparent words with opaque words to measure transparency effects. The 
results of the first contrast showed strong lexicality effects for transparent words. That is, transparent words were read more accurately than nonwords, $F_{1}(1,135)=14.60, \mathrm{MS}_{\mathrm{e}}=$ $9.97 ; F_{2}(1,68)=8.87, \mathrm{MS}_{\mathrm{e}}=8.10, p<.01$. The results of the second contrast revealed strong transparency effect, that is, transparent words were read more accurately than opaque words, $F_{1}(1,135)=358.73, \mathrm{MS}_{\mathrm{e}}=73.49 ; F_{2}(1,58)=39.32, \mathrm{MS}_{\mathrm{e}}=289.49$. These results corroborate the obtained lexicality and transparent effects from the latency analyses. The higher percentage of error rates for opaque words versus nonwords was an indicator of the lack of lexicality effects for opaque words. These results suggest that while orthographic skills are important in transparent word reading, phonological skills play a dominant role in opaque word reading. However, the pattern of skills used to read may differ based on children's grade levels.

More importantly, as predicted and in support of the latency analyses, there was a significant interaction between grade and stimuli, $F_{1}(6,135)=19.16, \mathrm{MS}_{\mathrm{e}}=27.53 ; F_{2}(6$, $97)=14.64, \mathrm{MS}_{\mathrm{e}}=32.07$. These results suggested that children's reading accuracy differed based on stimuli types across the grades. To determine lexicality effects for transparent words within each grade, the error rates for transparent words were compared to those for nonwords. The results showed that there was not a significant difference between error rates on transparent word and nonword reading in Grade 2, 3, and 4. This is possibly because of the low error rates for both transparent words and nonwords. However, although Grade 1 children read transparent words as fast as nonwords, error analyses suggest they read transparent words significantly more accurately than nonwords, $F_{1}(1,34)=21.64, \mathrm{MS}_{\mathrm{e}}=10.87 ; F_{2}(1,68)=11.01, \mathrm{MS}_{\mathrm{e}}=20.95, p<.01$ 
These results may suggest that children reach lexicalization of transparent words for accuracy earlier than for speed.

Similar to the latency analyses, the results for the error analyses showed that opaque words were always read less accurately than nonwords, $F_{1}(1,34)=116.24, \mathrm{MS}_{\mathrm{e}}$ $=55.44 ; F_{2}(1,68)=39.41, \mathrm{MS}_{\mathrm{e}}=160.20$ for Grade $1, F_{1}(1,34)=61.74, \mathrm{MS}_{\mathrm{e}}=54.05$; $F_{2}(1,68)=36.65, \mathrm{MS}_{\mathrm{e}}=89.19$ for Grade $2, F_{1}(1,34)=67.91, \mathrm{MS}_{\mathrm{e}}=43.71 ; F_{2}(1,68)=$ 28.31, $\mathrm{MS}_{\mathrm{e}}=102.73$ for Grade $3, F_{1}(1,33)=44.99, \mathrm{MS}_{\mathrm{e}}=9.35 ; F_{2}(1,68)=12.92, \mathrm{MS}_{\mathrm{e}}$ $=32.84, p<.01$ for Grade 4 children. These results indicated no lexicality effects for opaque words at any grade level.

The results for transparency effects based on error analyses supported those obtained from latency analyses. That is, children in all grades read transparent words more accurately than opaque words, $F_{1}(1,34)=178.04, \mathrm{MS}_{\mathrm{e}}=51.35 ; F_{2}(1,58)=46.61$, $\mathrm{MS}_{\mathrm{e}}=168.15$ for Grade $1, F_{1}(1,34)=76.38, \mathrm{MS}_{\mathrm{e}}=48.02 ; F_{2}(1,58)=30.17, \mathrm{MS}_{\mathrm{e}}=$ 104.20 for Grade $2, F_{1}(1,34)=73.68, \mathrm{MS}_{\mathrm{e}}=39.29 ; F_{2}(1,58)=20.57, \mathrm{MS}_{\mathrm{e}}=120.54$ for Grade $3, F_{1}(1,33)=54.56, \mathrm{MS}_{\mathrm{e}}=7.49 ; F_{2}(1,58)=9.44, \mathrm{MS}_{\mathrm{e}}=38.19, p<.01$ for Grade 4.

Word frequency. To provide converging evidence that the reduction in the size of the transparency effect may suggest involvement of orthographic skills in opaque word reading, the role of word frequency was examined. The examination of the association between the frequency judgments and the mean latencies for each word showed that higher frequencies were related to faster reading times for transparent words $(r=-.536, p$ $<.001)$ as well as opaque words $(r=-.557, p<.001)$. Therefore, these results revealed that both transparent and opaque words are sensitive to word frequencies. 


\section{Spelling Performance}

The role of phonological and orthographic skills on Persian spelling was examined through lexicality and polygraphy effects. Mean latencies, standard deviations, and error rates for spelling polygraphic words, nonpolygraphic words and nonwords are presented in Table 3. To evaluate children's spelling performance, a 4 × 3 Mixed Factor ANOVA was carried out with grade (4 levels: Grade 1 to 4 ) as a between-subject factor, and stimuli (3 levels: polygraphic words, nonpolygraphic words, and nonwords) as a within-subject factor on latencies and error rates, separately. The results of the latency analyses are presented first followed by the results of error analyses.

Analyses based on latency. There was a significant grade effect, $F_{1}(3,135)=$ $29.51, \mathrm{MS}_{\mathrm{e}}=69845.83 ; F_{2}(3,97)=249.01, \mathrm{MS}_{\mathrm{e}}=25847.72$, with older children spelling faster than younger children. Trend analyses were performed to evaluate the pattern of children's spelling progress across the grades. The results showed that both linear and quadratic differences were significant across the grades, $d=393$ for the linear effect and $d=150, \mathrm{p}<.01$ for the quadratic effect. These results revealed that children's overall spelling speed improved over time, although there was more of an improvement between Grades 1 and 2 than between Grades 3 and 4, $M_{s}=2494,2191,1982$, and 1978 for Grades 1 to 4 , respectively.

There was also a significant effect of stimuli, $F_{1}(2,135)=99.68, \mathrm{MS}_{\mathrm{e}}=$ $34925.65 ; F_{2}(2,97)=25.72, \mathrm{MS}_{\mathrm{e}}=191039.97$, with faster spelling speed for nonpolygraphic words, $M=2038$, followed by nonwords, $M=2109$, and polygraphic words, $M=2341$. A planned contrast compared nonpolygraphic words with nonwords to measure lexicality effects in spelling nonpolygraphic words. The results revealed 
significant lexicality effects, that is, nonpolygraphic words were spelled significantly faster than nonwords, $F_{1}(1,135)=12.16, \mathrm{MS}_{\mathrm{e}}=57114.23, p<.01$. The results of the item analyses were not significant, $F_{2}<1$. Note that, lexicality effects were not estimated for polygraphic words because they were spelled more slowly than nonwords as reported in Table 3. A planned contrast also compared nonpolygraphic word spelling with polygraphic word spelling. The results showed a significant polygraphy effect, that is, nonpolygraphic words were spelled significantly faster than polygraphic words, $F_{1}(1$, $135)=178.304, \mathrm{MS}_{\mathrm{e}}=71345.66 ; F_{2}(1,58)=33.08, \mathrm{MS}_{\mathrm{e}}=255899.02$.

Moreover, there was a significant overall interaction between grade and stimuli (3 levels: polygraphic words, nonpolygraphic words, and nonwords), $F_{1}(6,135)=4.35$, $\mathrm{MS}_{\mathrm{e}}=34925.65 ; F_{2}(6,97)=10.41, \mathrm{MS}_{\mathrm{e}}=25847.72$. To analyse lexicality effects for nonpolygraphic words within each grade, nonpolygraphic word spelling was compared with those of nonword spelling. There was not a significant difference between spelling speed of nonpolygraphic words and nonwords in any grade except Grade 2. Children in Grade 2 spelled nonpolygraphic words slightly faster than nonwords, $F_{1}(1,34)=13.18$, $\mathrm{MS}_{\mathrm{e}}=11776.14, p<.01 ; F_{2}(1,68)=4.68, \mathrm{MS}_{\mathrm{e}}=30340.10, p=.04$. As mentioned earlier and shown in Table 3, children never spelled polygraphic words faster or more accurately than nonwords. These results revealed no lexicality effects for spelling.

The analyses of polygraphy effects (nonpolygraphic vs polygraphic words) on children's spelling within each grade revealed that nonpolygraphic words were always spelled significantly faster than polygraphic words, $F_{1}(1,34)=37.17, \mathrm{MS}_{\mathrm{e}}=104373.05$; $F_{2}(1,58)=42.05, \mathrm{MS}_{\mathrm{e}}=135186.45$ for Grade $1, F_{1}(1,34)=79.37, \mathrm{MS}_{\mathrm{e}}=17530.31 ; F_{2}$ $(1,58)=25.29, \mathrm{MS}_{\mathrm{e}}=60840.37$ for Grade $2, F_{1}(1,34)=60.94, \mathrm{MS}_{\mathrm{e}}=13568.37 ; F_{2}(1$, 
$58)=17.67, \mathrm{MS}_{\mathrm{e}}=62772.97$ for Grade $3, F_{1}(1,33)=154.05, \mathrm{MS}_{\mathrm{e}}=6359.42 ; F_{2}(1,58)$ $=17.33, \mathrm{MS}_{\mathrm{e}}=75144.97$ for Grade 4 . These results suggested the presence of polygraphy effects in all grades. The examination of the difference between spelling polygraphic and nonpolygraphic words showed no systematic decrease in speed difference across grades, $d=471 \mathrm{~ms}$ for Grade $1, d=282 \mathrm{~ms}$ for Grade $2, d=218 \mathrm{~ms}$ for Grade 3 , and $d=241 \mathrm{~ms}$ for Grade 4 . Although there was a large difference between latencies of polygraphy words and nonwords for Grade 1 children, in other grades the differences were similar. These results again support the important role of phonological skills in Persian spelling. Analyses based on error rates. The results for the error analyses are consistent with those obtained from latency analyses. There was a significant effect of Grade, $F_{1}(3$, $135)=39.29, \mathrm{MS}_{\mathrm{e}}=15.04 ; \mathrm{F}_{2}(3,97)=26.43, \mathrm{MS}_{\mathrm{e}}=6.67$, with younger children making more errors than older children. The results of trend analyses revealed a significant linear effect on error rates, $d=7 \%$. These results suggested that children's overall spelling accuracy improved over time, $M_{s}=15 \%, 11 \%, 9 \%$, and $5 \%$, for Grades 1 to 4 , respectively.

There was also a significant effect of stimuli (3 levels: polygraphic words, nonpolygraphic words, and nonwords), $F_{1}(2,135)=650.18, \mathrm{MS}_{\mathrm{e}}=37.07 ; F_{2}(2,97)=$ $33.45, \mathrm{MS}_{\mathrm{e}}=651.07$ with higher errors on polygraphic words, $M=24.90 \%$, followed by nonwords, $M=2.30 \%$, and nonpolygraphic words, $M=1.70 \%$. The results of the planned analyses showed no lexicality effects for spelling nonpolygraphic words as there was not a significant accuracy difference between nonwords and nonpolygraphic words, $F_{l, 2}<1$. However, there was a strong polygraphy effect, that is, nonpolygraphic words were 
spelled significantly more accurately than polygraphic words, $F_{1}(1,135)=713.69, \mathrm{MS}_{\mathrm{e}}=$ $103.32 ; F_{2}(1,58)=29.78, \mathrm{MS}_{\mathrm{e}}=106.09$.

Moreover, there was an overall significant interaction between grade and stimuli (3 levels: polygraphic words, nonpolygraphic words, and nonwords), $F_{1}(6,135)=27.15$, $\mathrm{MS}_{\mathrm{e}}=37.07 ; F_{2}(6,97)=14.36, \mathrm{MS}_{\mathrm{e}}=63.67$. Taken together, the results of spelling based on error rates, similar to latencies, suggest that phonological skills play a dominant role in Persian spelling.

To analyse lexicality effects for nonpolygraphic words within each grade, the error rates in spelling nonpolygraphic words were compared with those of nonwords. The results revealed that children in all grades spelled nonpolygraphic words as accurately as nonwords, although Grade 1 children spelled nonpolygraphic words slightly more accurately than nonwords, $F_{1}(1,34)=6.98, \mathrm{MS}_{\mathrm{e}}=24.06, p<.05$. As mentioned earlier and shown in Table 3, children never spelled polygraphic words more accurately than nonwords which suggests there is no lexicality effect in spelling polygraphic words across grades.

Similar to the latency analyses, the results obtained from the analyses by error rates revealed that nonpolygraphic words were always spelled significantly more accurately than polygraphic words, $F_{1}(1,34)=437.20, \mathrm{MS}_{\mathrm{e}}=48.11 ; F_{2}(1,58)=34.72$, $\mathrm{MS}_{\mathrm{e}}=519.26$ for Grade $1, F_{1}(1,34)=153.54, \mathrm{MS}_{\mathrm{e}}=68.28 ; F_{2}(1,58)=23.29, \mathrm{MS}_{\mathrm{e}}=$ 385.84 , for Grade $2, F_{1}(1,34)=142.30, \mathrm{MS}_{\mathrm{e}}=56.97 ; F_{2}(1,58)=23.09, \mathrm{MS}_{\mathrm{e}}=301.01$ for Grade $3, F_{1}(1,33)=68.35, \mathrm{MS}_{\mathrm{e}}=32.72 ; F_{2}(1,58)=13.07, \mathrm{MS}_{\mathrm{e}}=151.01, p<.01$ for Grade 4. 


\section{Table 3}

Mean Correct Latencies in Milliseconds (Standard Deviations) and Percentages of Error Rates for Polygraphic Word, Nonpolygraphic Word, and Nonword Spelling for Grades 1 to 4 .

\begin{tabular}{|c|c|c|c|c|c|c|}
\hline \multirow[t]{2}{*}{ Grade } & \multicolumn{3}{|c|}{ Reaction Time } & \multicolumn{3}{|c|}{$\%$ Error } \\
\hline & Nonword & Nonpolygraphic & Polygraphic & Nonword & Nonpolygraphic & Polygraphic \\
\hline \multirow{2}{*}{1} & 2388 & 2312 & 2783 & 4.28 & 2.11 & 36.76 \\
\hline & $(386)$ & (293) & $(511)$ & $(4.01)$ & $(3.53)$ & $(9.16)$ \\
\hline \multirow[t]{2}{*}{2} & 2160 & 2066 & 2348 & 2.43 & 2.86 & 27.33 \\
\hline & (298) & $(246)$ & $(326)$ & $(2.31)$ & $(3.25)$ & $(11.80)$ \\
\hline \multirow[t]{2}{*}{3} & 1928 & 1900 & 2118 & 0.93 & 1.71 & 23.24 \\
\hline & $(266)$ & $(236)$ & $(273)$ & $(1.83)$ & $(2.60)$ & $(11.27)$ \\
\hline \multirow[t]{2}{*}{4} & 1954 & 1870 & 2111 & 1.25 & 0.39 & 11.86 \\
\hline & $(262)$ & $(200)$ & $(231)$ & $(2.32)$ & $(1.10)$ & $(8.05)$ \\
\hline
\end{tabular}


Word frequency. The examination of the association between word frequency and the mean latencies for each word showed no significant relation between frequency and nonpolygraphic words $(r=-.08, p=.67)$ which supports the previous findings that phonological skills play an essential role in spelling nonpolygraphic words. However, there was a significant relation between word frequency and polygraphic word spelling $(r$ $=-.403, p=.03)$. These findings suggest that spelling polygraphic words is sensitive to word related variables.

Difficulty Level between Reading and Spelling

To examine the difficulty level between reading and spelling, children's error rates were analysed separately for each grade with a 2 × 2 ANOVA with consistency (2 levels, transparent-nonpolygraphic words vs. opaque-polygraphic words) and task (2 levels, reading vs. spelling) as within-subject factors.

As expected, there was a significant main effect of consistency in all grades, $F_{1}(1$, $34)=549.41, \mathrm{MS}_{\mathrm{e}}=109.34 ; F_{2}(1,28)=91.79, \mathrm{MS}_{\mathrm{e}}=280.68$, for Grade $1, F_{1}(1,34)=$ $210.12, \mathrm{MS}_{\mathrm{e}}=145.19 ; F_{2}(1,28)=62.11, \mathrm{MS}_{\mathrm{e}}=210.52$, for Grade $2, F_{1}(1,34)=160.65$, $\mathrm{MS}_{\mathrm{e}}=142.99 ; F_{2}(1,28)=44.60, \mathrm{MS}_{\mathrm{e}}=220.89$, for Grade 3, and $F_{1}(1,33)=91.15, \mathrm{MS}_{\mathrm{e}}$ $=56.92 ; F_{2}(1,28)=13.32, \mathrm{MS}_{\mathrm{e}}=171.88, p<.01$ for Grade 4 . These findings revealed that opaque-polygraphic words were read and spelled significantly less accurately than transparent-nonpolygraphic words in all grades.

There was also a significant task effect, $F_{1}(1,34)=45.21, \mathrm{MS}_{\mathrm{e}}=116.84 ; F_{2}(1$, 28) $=6.91, \mathrm{MS}_{\mathrm{e}}=327.79, p=.01$ for Grade $1, F_{1}(1,34)=66.80, \mathrm{MS}_{\mathrm{e}}=98.54 ; F_{2}(1,28)$ $=12.22, \mathrm{MS}_{\mathrm{e}}=230.84, p<.01$ for Grade $2, F_{1}(1,34)=44.50, \mathrm{MS}_{\mathrm{e}}=87.90 ; F_{2}(1,28)=$ 
9.35, $\mathrm{MS}_{\mathrm{e}}=179.22, p<.01$ for Grade 3 , and $F_{1}(1,33)=26.85, \mathrm{MS}_{\mathrm{e}}=46.78 ; F_{2}(1,28)=$ $6.27, \mathrm{MS}_{\mathrm{e}}=88.34, p=.01$ for Grade 4. These findings showed that both types of words were read more accurately than they were spelled in all grades. However, this finding must be interpreted in the context of significant interactions

There was a significant interaction between task and consistency, $F_{1}(1,34)$ $=53.51, \mathrm{MS}_{\mathrm{e}}=111.35 ; F_{2}(1,28)=7.79, \mathrm{MS}_{\mathrm{e}}=327.79, p<.01$ for Grade $1, F_{1}(1,34)=$ $64.24, \mathrm{MS}_{\mathrm{e}}=102.46 ; F_{2}(1,28)=12.22, \mathrm{MS}_{\mathrm{e}}=230.84, p<.01$ for Grade $2, F_{1}(1,34)=$ $59.71, \mathrm{MS}_{\mathrm{e}}=70.31 ; F_{2}(1,28)=10.04, \mathrm{MS}_{\mathrm{e}}=179.22, p<.01$ for Grade 3 , and $F_{1}(1,33)$ $=25.30, \mathrm{MS}_{\mathrm{e}}=46.50 ; F_{2}(1,28)=5.88, \mathrm{MS}_{\mathrm{e}}=, p<.05$ for Grade 4. As presented in Figure 3, these results revealed that the size of the consistency effect was larger in spelling than reading.

The analyses of simple main effects showed that there were no significant differences between reading and spelling transparent-nonpolygraphic words within each grade, all $p_{s}>.30$. Children showed high accuracy levels for both reading and spelling transparent-nonpolygraphic words. However, in all grades opaque-polygraphic words were spelled less accurately than they were read, $t(34)=7.18, \mathrm{SE}=3.52$ for Grade $1, t$ $(34)=8.23, \mathrm{SE}=3.33$ for Grade $2, t(34)=7.25, \mathrm{SE}=2.96$ for Grade 3 , and $t(34)=$ $5.12, \mathrm{SE}=2.33$ for Grade 4 . These results may suggest that polygraphy affects spelling more than transparency affects reading. This possibility was examined using the following analyses. 
Figure 3

Interaction between Consistency across Reading and Spelling Tasks

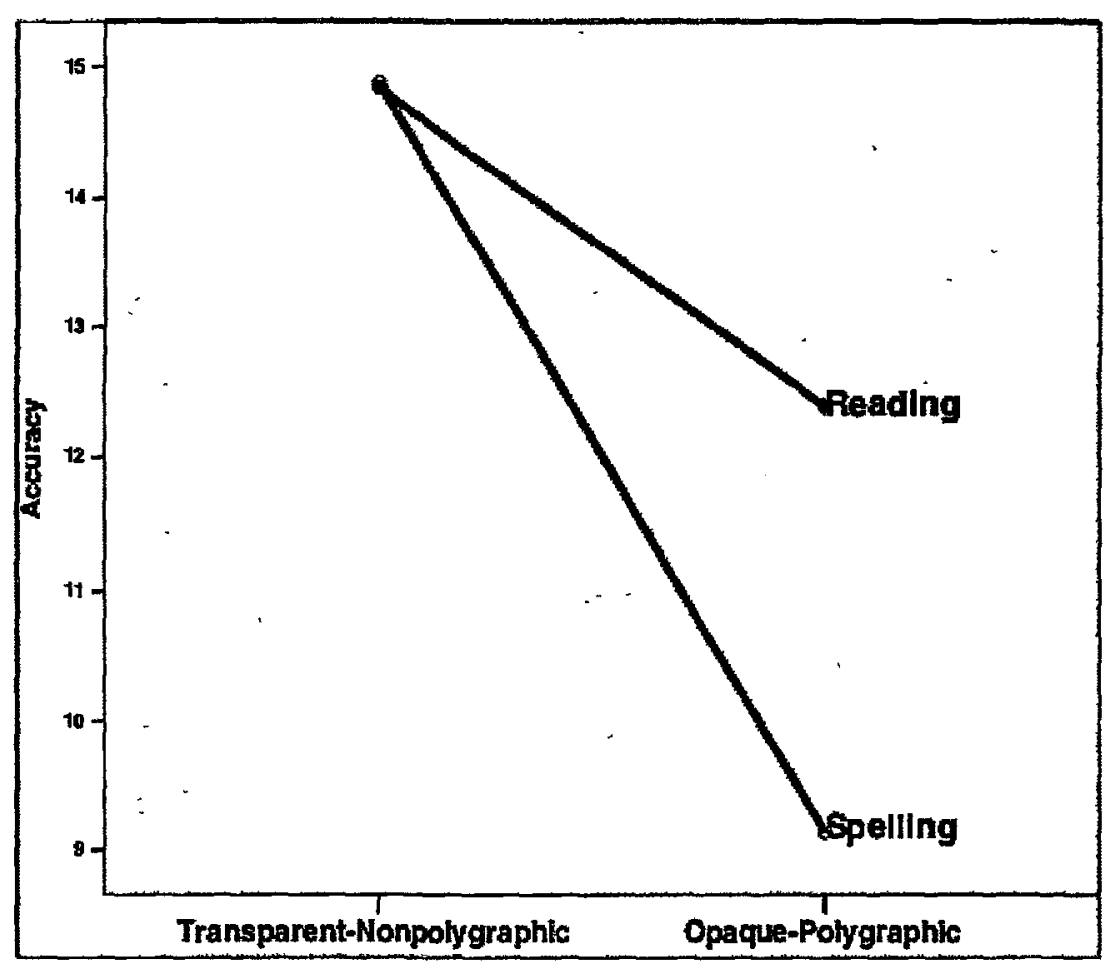




\section{Degree of Spelling Inconsistencies}

To explore the possibility that the degree of Persian spelling inconsistencies affects children's performance, the polygraphic word list ( $30 \mathrm{items})$ was divided into two categories: 1) polygraphic words with one polygraphic letter (15 items) and 2) polygraphic words with two polygraphic letters (15 items). Mean latencies, standard deviations, and error rates for spelling polygraphic words with one polygraphic letter and those with two polygraphic letters are presented in Table 4. A $4 \times 2$ Mixed Factor ANOVA was carried out with grade (4 levels: Grade 1 to 4 ) as between-subject factor, and inconsistency ( 2 level; words with one polygraphic letter vs. words with two polygraphic letters) as within-subject factor.

The results showed a significant effect of grade on both latencies, $F_{1}(3,135)=$ $27.89, \mathrm{MS}_{\mathrm{e}}=265480.10 ; F_{2}(3,28)=92.75, \mathrm{MS}_{\mathrm{e}}=41283.89$, and on error rates, $F_{1}(3$, $135)=35.27, \mathrm{MS}_{\mathrm{e}}=208.05 ; F_{2}(3,28)=16.14, \mathrm{MS}_{\mathrm{e}}=162.07$. These results, as mentioned in earlier analyses, suggest that the inconsistencies of Persian spelling affected younger children's spelling performance more than that of older children.

More importantly, there was also a significant effect of inconsistency on both latencies, $F_{1}(1,135)=164.18, \mathrm{MS}_{\mathrm{e}}=50269.64 ; F_{2}(1,28)=33.13, \mathrm{MS}_{\mathrm{e}}=173807.71$, and error rates, $F_{1}(1,135)=633.73, \mathrm{MS}_{\mathrm{e}}=94.04 ; F_{2}(1,28)=16.06, \mathrm{MS}_{\mathrm{e}}=1414.09$. These results revealed that words with one polygraphic letter were spelled more accurately $(M=10 \%$, error rates) and faster $(M=2197)$ than the words with two polygraphic letters, $M=40 \%$ for error rates and $M=2541$ for latencies. The interaction between grade and inconsistency was only significant in the subject analyses for error 
rates, $F_{1}(3,135)=13.52, \mathrm{MS}_{\mathrm{e}}=97.04, p<.01$. These results revealed that the size of inconsistency in terms of accuracy differed across the grades.

The examination of the simple main effects within each grade separately revealed that in all grades words with one polygraphic letter were spelled significantly faster than words with two polygraphic letters, $F_{1}(1,34)=23.61, \mathrm{MS}_{\mathrm{e}}=109299.62 ; F_{2}(1,28)=$ 19.91, $\mathrm{MS}_{\mathrm{e}}=127110.36$ for Grade $1, F_{1}(1,34)=35.39, \mathrm{MS}_{\mathrm{e}}=34168.45 ; F_{2}(1,28)=$ $11.97, \mathrm{MS}_{\mathrm{e}}=57204.56, p<.01$, for Grade $2, F_{1}(1,34)=61.12, \mathrm{MS}_{\mathrm{e}}=34293.94 ; F_{2}(1$, 28) $=24.04, \mathrm{MS}_{\mathrm{e}}=52089.99$ for Grade 3 , and $F_{1}(1,33)=112.32, \mathrm{MS}_{\mathrm{e}}=22499.77 ; F_{2}$ $(1,28)=25.99, \mathrm{MS}_{\mathrm{e}}=61254.46$ for Grade 4 .

Similar results were obtained for error analyses, that is, in all grades words with one polygraphic letter were spelled significantly more accurately than words with two polygraphic letters, $F_{1}(1,34)=275.66, \mathrm{MS}_{\mathrm{e}}=97.74 ; F_{2}(1,28)=11.93, \mathrm{MS}_{\mathrm{e}}=738.78, p$ $<.001$, for Grade $1, F_{1}(1,34)=211.84, \mathrm{MS}_{\mathrm{e}}=85.60 ; F_{2}(1,28)=12.68, \mathrm{MS}_{\mathrm{e}}=542.47, p$ $<.01$ for Grade $2, F_{1}(1,34)=119.74, \mathrm{MS}_{\mathrm{e}}=125.75 ; F_{2}(1,28)=14.04, \mathrm{MS}_{\mathrm{e}}=396.42, p$ $<.01$ for Grade 3, and $F_{1}(1,33)=71.98, \mathrm{MS}_{\mathrm{e}}=78.53 ; F_{2}(1,28)=11.20, \mathrm{MS}_{\mathrm{e}}=222.65$, $p<.01$ for Grade 4. Hence, the degree of spelling inconsistencies affected children's spelling performance in all grades. 
Reading and Spelling in Persian 65

Table 4

Mean Correct Latencies in Milliseconds (Standard Deviations) and Percentages of Error Rates for Polygraphic Words with One Polygraphic Letter and Polygraphic Words with Two Polygraphic, Letters Spelling for Grades 1 to 4.

\begin{tabular}{ccccc}
\hline \multirow{2}{*}{ Grade } & \multicolumn{2}{c}{ Reaction Time } & \multicolumn{3}{c}{$\%$ Error } \\
\cline { 2 - 5 } & $\begin{array}{c}\text { One-Letter } \\
\text { Polygraphic }\end{array}$ & $\begin{array}{c}\text { Two-Letter } \\
\text { Polygraphic }\end{array}$ & $\begin{array}{c}\text { One-Letter } \\
\text { Polygraphic }\end{array}$ & Two-Letter \\
\hline 1 & 2635 & 3018 & 17.14 & 56.38 \\
2 & $(431)$ & $(705)$ & $(8.90)$ & $(13.66)$ \\
& 2242 & 2505 & 11.24 & 43.43 \\
3 & $(328)$ & $(389)$ & $(8.82)$ & $(16.91)$ \\
& 1969 & 2316 & 8.57 & 37.91 \\
& $(261)$ & $(342)$ & $(8.64)$ & $(17.42)$ \\
& 1934 & 2320 & 2.75 & $(13.54)$ \\
\hline
\end{tabular}




\section{Discussion}

In the present study we investigated the relative importance of phonological and orthographic skills in Persian reading and spelling development at different grade levels. Moreover, the relative difficulty level of Persian reading and spelling was compared across grades.

\section{Skills Used to Read Persian}

The results of the present research suggest that children rely on both phonological and orthographic skills to read Persian, although the relative importance of these skills differed with word type and reading experience. These differences are described further below.

In the present study, the results for transparent word reading showed strong lexicality effects. That is, transparent words were read significantly faster and more accurately than transparent nonwords. These results suggest that transparent word reading in Persian relies on orthographic skills. However, the patterns differed based on academic experience. The current results revealed that lexicality effects did not appear in transparent word reading in all grade levels. Grade 1 children read transparent Persian words as fast as transparent nonwords, however from Grade 2 onward, children read transparent words significantly faster than transparent nonwords. These results are consistent with findings from studies in other orthographies (e.g., Waters et al., 1984) showing that phonological skills play an important role in younger children's reading, whereas orthographic skills are involved in older children's reading. In addition, the present results revealed that academic experience also led to an increase in the size of the 
obtained lexicality effects for transparent words across the grades. The speed differences between transparent words and nonwords increased as the grades progressed. Although transparent words in Grade 1 were read $36 \mathrm{~ms}$ slower than nonwords, transparent words were read faster than nonwords in Grade 2, $140 \mathrm{~ms}$; Grade 3, $173 \mathrm{~ms}$; and Grade 4, 255 ms. These results revealed that children's orthographic skills improved with reading experience.

The pattern of skills used to read opaque words was different than transparent word reading. There were no lexicality effects in any grade for opaque word reading, that is, opaque words were never read faster or more accurately than nonwords. In addition, there was a strong transparency effect within all grades. That is, in all grades transparent words were read significantly faster and more accurately than opaque words. These results support the idea that opaque word reading relies on phonological skills in Persian (Baluch \& Shahidi, 1991, Rahbariet al., 2007). Rahbari et al. (2007) found that the unique contribution of phonological skills (18\%) was substantially higher than that of orthographic skills (3\%) when children were required to read a list of words of which $90 \%$ were opaque.

Although the presence of a transparency effect together with the lack of lexicality effects in the present study may highlight the important role of phonological skills in opaque word reading, it was shown that the magnitude of the transparency effect decreased as grades progressed. That is, the differences between transparent and opaque words observed for younger children tended to be smaller in older children's reading. For instance, while the difference between transparent and opaque words in Grade 1 was $1206 \mathrm{~ms}$, it dropped substantially to $288 \mathrm{~ms}$ in Grade 4. These findings are consistent 
with the evidence from other studies showing that inconsistencies/irregularities have a larger affect on young children's reading performance compared to older children's reading (e.g., Alegria \& Mousty, 1994, 1996; Bachman, Bruck, Hebert, \& Seidenberg, 1984; Weekes, Castles, \& Davies, 2006). In addition to the reduction in the size of transparency effect, although opaque words were never read faster than nonwords in the present study, the differences between opaque word and nonword reading decreased systematically across the grades, so that Grade 4 children read opaque words as fast as nonwords. These word reading patterns may suggest children do not exclusively rely on phonological skills when reading opaque words, but that orthographic skills may also be involved in the reading development of these words. If opaque words were read solely by relying on phonological skills, the size of transparency effect as well as the difference between word and nonword reading would be the same across the grades. This interpretation is further supported by the results of the association between opaque word reading and word frequencies.

The examination of the correlation coefficients between word frequencies and reading latencies revealed that the correlation coefficients for both transparent $(r=-.53)$ and opaque $(r=-.55)$ words were statistically significant. That transparent word reading is sensitive to word frequencies further supports findings that orthographic skills play an essential role in transparent word reading. As Persian opaque words are also sensitive to word frequencies, it appears opaque words were not exclusively read by relying on phonological skills but orthographic knowledge was involved as well. The current evidence suggests both phonological and orthographic skills are involved in Persian word reading, although the dominant role of these skills differs based on word type. 
If one accepts the possibility that orthographic processes are also involved in opaque-word reading, then one has to also explain why opaque words were read more slowly and less accurately than transparent words across all grades. One possible explanation is that orthographic processes are sensitive to task demands or, more precisely, to the task at hand. Because Persian opaque words have missing vowels, access to their orthographic representation may take more time for transparent words for which the vowels are marked with letters. Recall that Persian opaque words appear as a sequence of consonant letters; consequently, a Persian reader has to select a correct vowel out of three alternatives (see Figure 1). This characteristic of Persian creates an additional challenge for reading opaque words. Further support for this interpretation comes from the findings obtained from Persian adults showing that Persian adults relied on orthographic processes to read both transparent and opaque words, but opaque words were still read significantly slower than transparent words (Rahbari \& Sénéchal, 2008).

Taken together, the increments in the size of lexicality effects together with the reductions in the size of transparency effects in Persian reading across the grades indicate gradual development of orthographic skills in Persian word reading. As the lexical memory for increasing vocabulary develops, children begin to rely less on phonological skills and more on orthographic knowledge. These pattern of skills used to read Persian in the present study is consistent with the models of reading development proposed for English-speaking children (Ehri, 1994). The current findings support the notion that children start to develop their reading by using phonological skills and then, with sufficient practice, the words processed phonologically become stored in lexical memory 
(Ehri \& Robbins, 1992; Share, 1995, 1999). For instance, Ehri and Robbins (1992) reported that only English pre-readers and first graders who were able to decode used orthographic skills to read a word, unlike those unable to decode. Therefore, phonological skills appear to be fundamental skills in children's reading development in many orthographic systems regardless of orthographic depth. This notion is also supported by other findings in Persian (e.g., Gholamain \& Geva, 1999)

Gholamain and Geva (1999) tested, among other measures, the reading performance of Persian-English children from Grade 1 to 5 on familiar and unfamiliar words. In their study, familiar words were those that are typically taught as vocabulary in Grades 1 to 5 of the Persian school program while unfamiliar words did not appear in the Persian curriculum. Results showed that Grade 1 and 2 children read familiar words significantly more accurately than unfamiliar words, whereas children from Grade 3 onward read familiar words as accurately as words they never practiced as part of their curriculum. These results are consistent with the findings of the present study showing that once Persian children gain sufficient experience with phonological skills, their reading performance becomes more accurate and they are able to read words they have heard but have never practiced. Gholamain and Geva, however, did not control for word type, namely, transparent and opaque words in each category of familiar and unfamiliar words. Future research may examine the patterns of reading development for transparent and opaque words separately based on the function of familiarity.

The current finding that children started to read by relying on phonological skills and then shifted to relying on orthographic knowledge is further supported by the evidence showing that orthographic skills play a dominant role in Persian adults' reading 
(Baluch \& Besner, 1991; Baluch \& Besner, 2001; Rahbari \& Sénéchal, 2008). The present finding can be compared directly with Rahbari and Sénéchal's (2008) study of young Persian adults because the same stimuli and methodology were used. Their results showed a strong lexicality effect for both transparent and opaque words suggesting that orthographic skills played a dominant role in both transparent and opaque word reading by young Persian adults. In Rahbari and Sénéchal, the finding that young adults relied on lexical knowledge to read transparent words is not surprising as children as young as Grade 2 in the present study applied orthographic skills to read transparent words. However, the findings that young adults read opaque words by applying orthographic skills suggest that opaque word reading in Persian reaches lexicalization after Grade 4.

The current within-orthographic study suggesting that transparent words are read faster and more accurately than opaque words provides further support for prior crossorthographic studies (e.g., Aro \& Wimmer, 2003; Durgunoglu \& Oney, 1999; Seymour et al., 2003) as well as single orthographic findings in transparent orthographies such as Turkish, Finnish, and Italian (e.g., Oney \& Durgunoglu, 1997; Holopainen, Ahonen, \& Lyytinen, 2005; Cossu, Gugliotta, \& Marshall, 1995) showing that children learning to read in transparent orthographic systems develop their reading faster and more accurately than children learning to read in less transparent orthographies. For example, it is argued that English-speaking children approach $90 \%$ of reading accuracy level 3 years later than the children learning to read in transparent orthographies (Aro \& Wimmer, 2003). This delay on English-speaking children's reading acquisition is attributed to the opaqueness of the English orthography. Similar to these findings, children in the present study 
showed above $95 \%$ accuracy for transparent word reading at the end of Grade 1 , whereas they reached close the same accuracy levels for opaque word reading at Grade 4.

The current results, however, do not support the orthographic depth hypothesis suggesting that phonological processes are the primary means for reading in transparent orthographic systems whereas orthographic skills are important in opaque orthographic systems. More importantly, the current findings qualify the statement that children learning to read in transparent orthographies enter the orthographic stage quite late due to availability of one-to-one correspondence rules (e.g., Sprenger-Charolles et al., 2003; Tressoldi, 1996). The current results for reading revealed that the availability of one-toone correspondence rules for transparent words helped children to learn these words very fast which, in turn, facilitated lexicalization processes for these words. These findings suggest that as more one-to-one correspondence rules are available, words are learned more easily and quickly become part of lexical memory. On the other hand, when there is not a one-to-one relation between letters and sounds (e.g., the opaque words in the present study), it takes longer for words to be learned and saved in lexical memory.

By contrast, the current results differ from the findings of Arab-Moghaddam and Sénéchal (2001) who reported that the unique contribution of orthographic (9\%) skills was higher than phonological skills (4\%) in bilingual Persian-English children's reading. In Arab-Moghaddam and Sénéchal, more than $83 \%$ of the words were opaque; thus, one may expect phonological skills rather than orthographic skills play a dominant role in reading these words, as it was the case in the current results. These discrepancies between the two studies may also be due to the methodological differences and/or the index used to test reading skills. The measures used to examine children's orthographic processing 
skills were different in Arab-Moghaddam and Sénéchal (2001) and that of the present study. In the present study, children's orthographic skills were measured by comparing children's performance in word and nonword reading in terms of accuracy and speed. However, in Arab-Moghaddam and Sénéchal, children's orthographic processing skills were examined by a forced-choice task in which children were presented with a word and pseudohomophone of that word and then required to select the correct word. Thus one possibility is that the use of different measures led to different patterns of findings. This possibility can be examined in future research when other variables such as subjectrelated factors are controlled. More importantly, the stimuli in Arab-Moghaddam and Sénéchal were such that the short vowels in opaque words were represented within words; therefore, the words were not truly opaque. When short vowels are included in printed Persian opaque words, they become entirely transparent because their phonemic structure can be easily assembled using grapheme-phoneme conversion rules. In fact, including short vowels with opaque words provides more orthographic information which, in turn, helps children retrieve the words from lexical memory. Thus, the pattern of word reading in Arab-Moghaddam and Sénéchal is indeed similar to the pattern of transparent word reading in the present study.

Skills Used to Spell Persian

In the present study, the results for Persian spelling were different from reading. The current results for spelling reveal that phonological skills play an essential role in Persian spelling. A detailed explanation of the pattern of the skills used to spell in Persian 
based on word types and academic experience highlight Persian children's spelling development.

In the present study, both word and nonword spelling improved in terms of speed and accuracy based on grade levels or academic experience. Children in higher grades spelled both words and nonwords faster and more accurately than did children in lower grades. These results are consistent with the findings from many studies showing a significant effect of age or grade levels in children's spelling (e.g., Lexon, Coltheart, \& Keating, 1988; Weekes et al., 2006). However, it seems that the quality of children's skills used to spell Persian words did not differ based on word types and/or academic experience. That is, the use of phonological skills in spelling was more salient than orthographic skills in spelling of both polygraphic and nonpolygraphic words in all grades. This was evident from the lack of a lexicality effect for both nonpolygraphic and polygraphic word spelling in all grades. Note that Grade 1 children spelled nonpolygraphic words slightly more accurately than nonwords. However, this was probably due to the fact that Grade 1 children were unable to remember all phonemes in a nonword correctly when spelling to dictation. At the time of testing, Grade 1 children had just finished learning all the letter sounds. The current results for spelling within each grade revealed that neither polygraphic nor nonpolygraphic words were spelled faster than nonwords. In particular, there was no systematic increment in the difference between words and nonwords spelling across grades. These findings suggest that children used the same skills, that is, phonological skills, to spell both words and nonwords in all grades. These results support the hypothesis that phonological skills play an essential role in spelling (Frith, 1979). 
In addition to the absence of lexicality effects, the current results revealed a strong polygraphy effect in spelling performance in all grades. That is, children in all grades spelled nonpolygraphic words more accurately and faster than polygraphic words. These results are consistent with the findings of cross-orthographic as well as within orthographic evidence showing that the rate of spelling acquisition is higher in consistent orthographies compared to inconsistent orthographies (e.g., Caravolas \& Bruck, 1993; Juul, 2005; Wimmer \& Landerl, 1997). However, the presence of a significant polygraphy effect in Persian children's spelling in all grades without a systematic reduction in the magnitude across grades is inconsistent with the research demonstrating that the consistency effect decreases by age or academic experience in the spelling performance of French-speaking (Alegria \& Mousty, 1994, 1996) or English-speaking children (e.g., Brown \& Loosemore, 1994a; Lexon et al., 1988; Weekes et al., 2006). These differences are probably due to the long lasting use of phonological skills in Persian compared to English or French where the use of orthographic skills are evident in young children's spelling (Treiman, 1993; Treiman et al., 1994; Pacton, Perruchet, Fayol, \& Cleeremans, 2001).

Further support for the results that phoneme-grapheme correspondence rules are dominant in Persian spelling comes from the examination of children's spelling errors across grades. In the present study, almost all of children's spelling errors in polygraphic words in all grades were predominantly phonological. That is, the misspelled words were phonologically correct and sounded like a target words, but children selected an incorrect grapheme for a particular phoneme which resulted in a pseudohomophone. Likewise, children's errors in nonpolygraphic words or nonwords generally were substitutions of a 
grapheme that had a similar sound to the target phoneme (e.g., $b$ instead $p$ ). This shows that Persian children were able to use phonological skills successfully, and consequently, analysed the spoken word into phonemes and represented each phoneme with a particular grapheme.

The current results regarding the important role of phonological skills in Persian spelling are consistent with the previous findings with monolingual Persian children (Rahbari et al., 2007) showing that the unique contribution of phonological skills (17\%) was substantially higher than that of orthographic skills (5\%) in Grade 2 children's spelling. Likewise, the current findings are consistent with findings obtained from other languages showing that children rely heavily on phonological skills to spell words in consistent orthographies. For example, Wimmer and Hummer (1990) examined error analyses and reported that Grade 1 German children strongly relied on knowledge of phonological information to spell German words. Similarly, in Greek, which is more consistent in terms of spelling than reading, children are highly likely to process spelling by relying on grapheme-phoneme correspondences (Porpodas, 1989a, 2001). In particular, the pattern of skills used to spell Persian in the present study are similar to those obtained from Italian children. Tressoldi (1996) reported that there was not a significant difference between error rates of nonwords and Italian real words. More importantly, the decrease in error rates from Grade 2 to 5 was not significant. The author reported that these results were indicators of the dominant role of phonological skills in both younger and older Italian children's spelling.

In addition to the current spelling results with Persian children, it seems that skilled spellers of Persian also rely on phonological skills or nonlexical processes to spell 
Persian (Rahbari \& Sénéchal, 2008). Similar to the current results, there was no lexicality effect either in polygraphic or nonpolygraphic words, although there was a strong polygraphic effect in young Persian adults' spelling performance. These results may suggest that the characteristics of Persian orthography encourage Persian spellers to rely on phonological skills to spell Persian regardless of their spelling skills and academic experience. These interpretations are supported by aspects of the findings obtained in a study that investigated the strategies used to spell new words by English-speaking children and adults (Kwong \&Varnhagen, 2005). The results of this study showed that some participants relied exclusively on phoneme-grapheme correspondence rules when these were fast and efficient (Kwong \& Varnhagen, 2005). This might also be the case for Persian spelling as both Persian children and young adults applied phonemegrapheme correspondence rules to spell Persian. It is possible that Persian spellers rely on phoneme-grapheme correspondence rules to spell Persian because these processes are easy, fast, and generally accurate.

Although the spelling results in the present study revealed that phonological skills played an essential role in spelling both Persian nonpolygraphic and polygraphic words, the examination of the correlation coefficients between word frequencies and word types showed a different correlation pattern for the two types of words. While the correlation between nonpolygraphic words and word frequencies was not statistically significant $(r=$ $-.08)$, the spelling latencies of polygraphic words were significantly correlated with word frequencies $(r=-.40)$. These results revealed that spelling performance with Persian polygraphic words was sensitive to the word frequencies whereas this was not the case for nonpolygraphic words. The finding that spelling of nonpolygraphic words was not 
sensitive to the word frequencies support the current findings that nonpolygraphic words were spelled by relying on phonological skills. However, the significant correlation between polygraphic word spelling and word frequencies may suggest that when one-toone phoneme-grapheme correspondences are not available, children may rely on other sources of information such as their orthographic knowledge acquired from exposure to words. This orthographic knowledge might be necessary to select the appropriate letter from the other available alternative letters for that polygraphic phoneme. As such, orthographic knowledge should indeed be sensitive to word frequency.

Evidence from other studies in Persian supports the notion that when one-to-one grapheme-phoneme correspondences are not available, orthographic knowledge may be involved in Persian spelling. Rahbari et al. (2007) reported the unique contribution of orthographic skills was almost twice as high when spelling polygraphic (7\%) than nonpolygraphic (3\%) words. In the other words, in Rahbari et al the unique contribution of phonological skills to spelling nonpolygraphic words (24\%) dropped significantly when spelling polygraphic words (8\%). These results suggest that Grade 2 Persian children applied both phonological and orthographic information when spelling polygraphic words. Taken together, the sensitivity of polygraphic word spelling to word frequencies in the present study together with the evidence from Rahbari et al. (2007) suggest that the polygraphy characteristic of the Persian orthography may force Persian spellers to use orthographic knowledge to spell polygraphic words correctly. These findings are compatible to the psycholinguistic- grain-size hypothesis for reading that postulates the use of orthographic skills is inevitable in opaque orthographies due to the limited availability of one-to-one correspondences (Perry \& Ziegler, 2000). 
That phonological skills played a dominant role in Persian spelling in the present study contrasts with the finding that orthographic skills played a strong role in ArabMoghaddam and Sénéchal (2001). In the Arab-Moghaddam and Sénéchal study, phonological skills did not account for any variability in spelling whereas orthographic skills accounted for $22 \%$ of unique variance in spelling. These discrepancies in results may be related to the length of the stimuli used to test spelling and/or subject-related factors. In Arab-Moghaddam and Sẻnéchal, the word list contained one-syllable, twosyllable, and multi-syllable words whereas the present study used almost all one-syllable words. It is possible that the length of stimuli influences skills used to spell Persian. When the length of a word is short, like the one-syllable words in the present study, a speller is able to remember all the phonemes in a word pronounced by an experimenter. Consequently, participants are able to easily represent a corresponding grapheme to each sound. When the length of a word is long, on the other hand, it is difficult to remember every single sound in a word and the semantic factor and/or orthographic knowledge may be used to spell familiar words. Therefore, it is possible that the length of words encouraged children in the present study and young adults in Rahbari et al. (2008) to use decoding strategies to spell one-syllable words as they may have found these strategies were fast and easy. Alternatively, discrepancies in skills used to spell Persian in ArabMoghaddam and Sénéchal and the current results may be related to participant characteristics. Since the children studied in Arab-Moghaddam and Sénéchal were bilingual, it is possible that these children generalized the skills used to spell in their second language, English, to their first language, Persian. 
Similarly, the current findings for spelling are inconsistent with the findings of other studies showing that children use their orthographic knowledge to spell words very early in their education (Cassar \& Treiman, 1997; Pacton et al., 2001). For example, Cassar and Treiman (1997) examined use of orthographic knowledge in English spelling by testing children's knowledge of the use of letter doublets in English. In this study children were shown nonword pairs and asked them to choose the nonword that looked more like a real word. They compared legal and illegal doublets in the final and initial positions of the word. The results showed that Grade 1 English children chose nonwords with final doublets (legal) more often than they chose nonwords with initial or illegal doublets (e.g., mmom, ckat). Similar results were reported by Pacton et al. (2001) who investigated French-speaking children's performance in an orthographic constraint test. Pacton and colleagues investigated children's learning of doublet position rules by using doublets that are never doubled. That both French and English speaking children were able to use orthographic information very early in their education may be attributed to the characteristics of orthographic systems of these languages which are highly inconsistent in terms of spelling.

Interestingly, it was also reported that Finnish children who just started school used orthographic information more than phonological skills to distinguish between two pseudowords the one that looked more like a real word (Lehtonen, 2006). In contrast to English and French, Finnish has a very transparent orthography in terms of both reading and spelling; therefore, one may expect that these children use phonological skills early in their education more than orthographic skills, like young Persian children in the present study or children from other transparent orthographies (e.g., Italian; Tressoldi, 
1996). The main methodological differences between the study with Finnish children and the present study, however, is that in the present study Persian children were required to write the spelling of a word pronounced by an experimenter. In contrast, Finnish children had to select the correct spelling from two options. In addition, children in the present study used auditory stimuli to spell a word, whereas Finnish children used visual cues to discriminate the correct letter patterns from incorrect ones. It is possible that when children concurrently observe the correct and incorrect spelling of a word, the visual cues facilitate the use of orthographic skills. However, in the traditional way of writing to dictation, auditory cues may induce children to apply phonological skills. Therefore, the skills children use to spell may be affected by the type of a spelling task applied. This interesting possibility can be tested in future research by requiring children to spell words presented in one of two modes, auditory and visually, while controlling for other variables.

\section{Relative difficulty level between Persian reading and spelling}

With regard to the relation between reading and spelling in terms of difficulty level, the current results showed no significant difference between reading and spelling transparent-nonpolygraphic words. However, children made more errors spelling polygraphic-opaque words than they did reading the same words. These results suggest that when consistency levels are controlled for both reading and spelling, children spell words as accurately as they read the same words. These findings are compatible with research on bidirectionally transparent orthographies, that is, transparent in terms of both reading and spelling. For instance, the evidence from Finnish (Aro et al., 2004), Turkish 
(Oney et al., 1997) and Italian (Thorstad, 1991) orthographies reveal the same accuracy level and development for reading and spelling. However, evidence from orthographies that are more consistent in terms of reading than spelling reveal higher accuracy (Sprenger-Charolles et al., 2003) and faster development for reading than spelling (e.g., Pinheiro, 1995). Thus, the current findings qualify general statements that attribute the accuracy differences in children's reading and spelling performance to the higher difficulty level of the spelling task in comparison to the reading task (e.g., Eme \& Golder, 2005; Goswami \& Bryant, 1990; Sprenger-Charolles et al., 2003).

A question arising from the current findings is why polygraphic-opaque words were read more accurately than they were spelled. One possible explanation is that Persian orthography, like many other orthographic systems such as English (Ziegler et al., 1997), French (Ziegler et al., 1996), and German (Wimmer \& Mayringer, 2002), is more inconsistent in terms of phoneme-grapheme correspondences than graphemephoneme correspondences. There are no statistical analyses available that consider the relative complexity levels of Persian reading and spelling. However, recall that the source of complexities in terms of grapheme-phoneme correspondences in Persian is limited to a selection of a correct short vowel out of three possible choices. In contrast, there are six phonemes in Persian that can be marked by more than one letters, with some phonemes (e.g., /z/) represented by four different letters. Therefore, it seems that the Persian orthography is more complex in terms of spelling than reading. This idea is further supported by the evidence showing that Grade 2 Persian children perform significantly better in reading ( $72 \%)$ opaque words than spelling polygraphic words (46\%), but that their spelling accuracy for nonpolygraphic words was also highly accurate (86\%, Rahbari 
et al., 2007). Therefore, the low spelling accuracy levels for polygraphic-opaque words in the current study may be attributed to the higher orthographic complexities of Persian in terms of spelling than in reading.

Another reason why there were discrepancies in accuracy between reading and spelling complex words is that, in the present study, some polygraphic words contained more than one polygraphic letter, adding to the difficulty level of these words. The comparison between polygraphic words with one polygraphic letter and those with two polygraphic letters showed that polygraphic words with one polygraphic letter were spelled more accurately than the words with two polygraphic letters. In fact, the degree of complexities for some polygraphic words was very high in the present study. There is prior evidence showing that the degree of inconsistencies affects participant performance. For instance, Ziegler, Ferrand and Montant (2004) revealed that inconsistent French words with less-dominant spelling produced longer latencies and more errors than inconsistent words with dominant spelling. Likewise, Jared (1997) showed that exception words (both irregular and inconsistent words) produced significantly longer naming latencies than matched regular-inconsistent words for English-speaking participants (Experiment 4). These findings suggest that the degree of complexity affects participant performance. In particular, in the present study polygraphic-opaque words were more inconsistent; among 15 polygraphic-opaque words, 11 words contained two polygraphic letters, whereas only 4 polygraphic-opaque words contained a single polygraphic letter. Thus, participants made more errors when spelling polygraphic-opaque words than reading the same words due to the higher degree of the complexity in terms of Persian 
spelling than reading. Therefore, it is the degree of complexity that generally makes spelling task more difficult than reading, not the task by itself as some authors believe.

Limitation and suggestion for future research

The results of the present study are limited to only monosyllabic items and generally items with three letters. The size of the transparency and lexicality effects may differ with the length of items used to test reading and spelling. In particular, the current results that children in all grades relied on phonological skills to spell words raises the possibility that the skills children use to spell words may be influenced by the length of the words. This possibility can be tested by future research by using words that vary in length.

It may also be that the skills children use to spell are affected by the type of task used to measure the spelling performance. It is possible that when spelling stimuli are presented auditory versus visually, different parts of the brain representing different skills are activated. Therefore, future research may examine skills used to spell Persian when using other methods rather than the traditional writing to dictation method used in the present study. For instance, children may be presented with an object or a picture of a target word and required to spell the related word.

In the present study, it was shown that polygraphic words with two polygraphic letters were more difficult to spell than those containing one polygraphic letter. It would be also interesting to examine whether it is more difficult to spell words containing a phoneme represented by 4 graphemes (e.g., /z) than words containing a phoneme represented only by 2 graphemes (e.g., /t). This possibility can be examined by precisely 
controlling the type of polygraphic letter within each category of polygraphic words with two or more alternative graphemes. Note that the position of the polygraphic phonemes in a polygraphic word may also influence latencies when measuring the onset of spelling latencies.

In addition, it is helpful to consider the cursive and disjointed nature of Persian writing when measuring spelling latencies. The Persian spelling, unlike English spelling, is written with a mixture of cursive and disjointed letters, that is, some of the words in Persian have a mandatory spelling in which all or some of the letters have to be written in a joined fashion whereas other words have to be written disjointed or separately. This characteristic of Persian writing, which is independent of polygraphy/nonpolygraphy effects, may affect the spelling latencies, especially when whole spelling latencies are measured rather than the onset of spelling latencies.

Finally, although the results in the present study reveal that phonological skills play a dominant role in Persian spelling, a significant correlation coefficient between word frequencies and polygraphic words may suggest orthographic knowledge is involved when spelling polygraphic words. This interesting possibility can be investigated in future research by comparing spelling performance for high and low frequency polygraphic words when other word-related variables are controlled.

\section{Conclusion}

The results for reading, in the present study, support developmental models of reading in English (Ehri, 1994) that suggest that children start to develop their reading by using phonological skill and with sufficient experience, then rely on orthographic skills to read words. Therefore, the pattern of skills used to read are not language dependent, but 
children follow similar patterns to develop reading skills in many orthographies. However, given that Persian transparent words are read more accurately and reach lexicalization faster than opaque words suggest that the transparency of an orthography helps children develop their reading more quickly.

Although the current results suggest that spelling is not more difficult than reading when consistency levels of words are controlled in terms of reading and spelling, the pattern of skills used in Persian spelling differ from skills used for reading. While both phonological and orthographic skills were important in Persian reading, phonological skills were dominant in Persian spelling. These results support the notion that children reading and spelling pursue different patterns of strategies (Bryant \& Bradley, 1980; Caravolas, Hulme \& Snowling, 2001; Frith, 1980; Goswami \& Bryant 1990). According to these authors, alphabetic principles play a role in children's spelling, but visual cues are more evident in their reading. Further support for this comes from studies presenting evidence that a separate orthographic representation is used to access reading versus spelling (e.g., Hanly \& Kay, 1992). It is, also, possible that characteristics of the Persian orthography in terms of phoneme-to-grapheme correspondences encourages Persian spellers to rely more on phonological processes.

Finally, it is concluded that the processes children use to read and spell are not due to differences in consistency across orthographic systems, but these processes may be influenced by the characteristics of words within orthographies and participants' experience. 


\section{References}

Aaron, P.G. A., Joshi, R. M., Ayotollah, M., Ellsberry, A., Henderson, J., \& Lindsey, K. (1999). Decoding and sight-word naming: Are they independent components of word recognition skill? Reading and writing, 11, 89-127.

Adams, M. (1990). Beginning to read: Thinking and learning about print. Cambridge, MA: MIT Press.

Alegria, J., \& Mousty, P. (1994). On the development of lexical and non-lexical spelling procedures in French-speaking normal and disabled children. In G.D.A. Brown \& N. Ellis (Eds), Handbook of spelling: Theory, process and intervention (pp. 211226). Chichester: Wiley.

Alegria, J., \& Mousty, P. (1996). The development of spelling procedures in Frenchspeaking, normal and learning disabled children: Effects of frequency and lexicality. Journal of Experimental Child Psychology, 63, 312-338.

Arab-Moghaddam, N., Sénéchal, M. (2001). Orthographic processing skills in reading and spelling in Persian/ English bilinguals. International Journal of Behavioral Development, 25 (2), 140-147.

Aro, M., \& Wimmer, H. (2003). Learning to read: English in comparison to six more regular orthographies. Applied Psycholinguistics, 24, 619-634.

Bachman, J., Bruck, M., Hebert, M., \& Seidenberg, M. (1984). Acquisition and use of spelling-sound information in reading. Journal of Experimental Child Psychology, $38,114-133$.

Baluch, B., \& Besner, D. (1991). Visual word recognition: Evidence for strategic control of lexical and nonlexical routines in oral reading. Journal of Experimental 
Psychology, Learning, Memory, and Cognition, 17, 4, 644-652.

Baluch, B., \& Shahidi, S. (1991). Visual word recognition in beginning readers of Persian. Perceptual and Motor Skills, 72, 1327-1331.

Baluch, B., \& Besner, D. (2001). Basic process in reading: Semantics affects speeded naming of high-frequency words in an alphabetic script. Canadian Journal of Experimental Psychology, 55, 1, 63-69.

Baluch, B. (2006). Persian orthography and its relation to literacy. In R. M. Joshi \& P.G. Aaron (Eds.), Hand book of orthography and literacy (pp. 365-376). NJ: Lawrence Erlbaum Associates.

Baluch, B. (1993). Lexical decision in Persian: A test of the orthographic depth hypothesis. International Journal of Psychology, 28,19-29.

Barry, C. (1994). Spelling rotes (or roots or rutes). In G.D.A. Brown \& N.C. Ellis (Eds.), Handbook of spelling: Theory, process and intervention (pp. 27-49). Chichester: Wiley.

Basso, A., \& Paulin, M. (2003). Semantic errors in naming, repetition, spelling and drawing from memory: A new Italian case. Neurocase, 9, 109-117.

Bowey, J.A, \& Muller, D. (2005). Phonological recoding and rapid orthographic learning in third-graders' silent reading: A critical test of the self-teaching hypothesis. Journal of Experimental Child Psychology, 92, 3, 203-219.

Brown, G.D.A., \& Loosemore, R. P. W. (1994a). Computational approaches to normal and impaired spelling. In G. D. A. Brown \& N. Ellis (Eds.), Handbook of spelling: Theory, Process and intervention (pp.319-335). Chichester: Wiley.

Bruck, M., Genesee, F., \& Caravolas, M. (1997). A cross-linguistic study of early literacy acquisition. In B. A. Blachman (Ed.), Foundations of reading acquisition and 
dyslexia: Implications for early intervention (pp. 145-162). Mahwah, NJ: Erlbaum. Bruck, M., \& Waters, G.S. (1988). An analysis of spelling errors of children who differ in their reading skills. Applied Psycholinguistics, 9, 77-92.

Bruck, M. \& Waters, G.S. (1990). An analysis of the component spelling and reading skills of good readers-good spellers, good readers-poor spellers, and poor readerspoor spellers. In T.H. Carr \& B.A. Levy (Eds.), Reading and its development: Component skills approaches (pp. 161-206). San Diego: Academic Press. Caravolas, M., \& Bruck, M. (1993). The effect of oral and written language input on children's phonological awareness: A cross linguistic study. Journal of Experimental Child Psychology, 55, 1-30.

Caravolas, M., Hulme, C., \& Snowling, M. (2001). The foundations of spelling ability: Evidence from a 3-year longitudinal study. Journal of Memory and Language, $45,751-774$.

Caravolas, M., Kessler, B., Hulme, C., \& Snowling, M. (2005). Effects of orthographic consistency, frequency, and letter knowledge on children's vowel spelling development. Journal of Experimental Child Psychology, 92, 307-321.

Cassar, M., \& Treiman, R. (1997). The beginnings of orthographic knowledge: Children's knowledge of double letter in words. Journal of Experimental Psychology, 89, 631-644.

Coenen, M.J.W.L., Van Bon, W.H. J., \& Schreuder, R. (1997). Reading and spelling in Dutch first and second graders: Do they use an orthographic strategy? In C.K. Leong \& R.M. Joshi (Eds.), Cross-language studies of learning to read and spell (pp, 249-269). Kluwer: Academic Press. 
Corcos, E., \& Willwos, D.M. (1993). The role of visual processing in good and poor readers' utilization of orthographic information in letter strings. In S. F. Wright \& R. Groner (Eds.), Facets of dyslexia and its remediation (pp. 95-106). Amsterdam: Elsevier Science.

Cossu, G., Gugliotta, M., \& Marshall, J. C. (1995). Acquisition of reading and written spelling in a transparent orthography: Two non-parallel processes? Reading and Writhing, 7, 9-22.

Cunningham, A.E., Perry, K.E., Stanovich, K.E., \& Share, D.L. (2002). Orthographic learning during reading: Examining the role of self-teaching. Experimental Child Psychology, 82, 185-199.

Defior, S., Martos, F., \& Cary, L. (2002). Differences in reading acquisition development in two shallow orthographies: Portuguese and Spanish. Applied Psycholinguistics, $23,135-148$.

Defior, S., \& Serrano, F. (2005). The initial development of spelling in Spanish: From global to analytical. Reading and Writing, 18, 81-98.

Durgunoglu, A.Y., \& Oney, B. (1999). A cross-linguistic comparison of phonological awareness and word recognition. Reading and Writing: An Interdisciplinary Journal, 11, 281-299.

Ehri, L.C., \& Wilce, L.S. (1983). Development of word identification speed in skilled and less skilled beginning readers. Journal of Educational Psychology, 75(1), 318.

Ehri, L.C., \& Wilce, L.S. (1987). Cipher versus cue reading: An experiment in decoding acquisition. Journal of Educational Psychology, 79, 3-13. 
Ehri, L.C., \& Robbins, C. (1992). Beginners need some decoding skill to read words by analogy. Reading Research Quarterly, 27, 12-26.

Ehri, L.C. (1992). Review and commentary: Stages of spelling development. In S. Templeton \& D.R. Bear (Eds), Development of orthographic knowledge and the foundations of literacy: Amemorial festschrift for Edmund $H$. Henderson (pp. 307-332). Hillsdale, NJ: Erlbaum.

Ehri, L. (1994). Development of the ability to read words. In R. Ruddell, M. Ruddell, \& H. Singer (Eds.), Theoretical models and processes of reading (pp. 323-358), Newark, DE: International Reading Association.

Ehri, L.C. (200). Learning to read and learning to spell: Two sides of a coin. Topic in language Disorder, 20(3), 19-36.

Ehri, L. (2005). Learning to read words: theory, findings, and issues. Scientific Studies of Reading, 9, 2, 167-188.

Eme, E. \& Golder, C. (2005). Word-reading and word-spelling of French beginners: Do all children learn to read and spell in the same way? Reading and Writing, 18, 157-188.

Fitzgerald, J., \& Shanahan T. (2000). Reading and writing relations and their development. Educational Psychology, 35, 39-51.

Fletcher-Flinn, C., Shankweiler, D., \& Frost, S. (2004). Coordination of reading and spelling in early literacy development: An examination of the discrepancy hypothesis. Reading and Writing: An Interdisciplinary Journal, 17, 617-644. Foorman, B.R., Francis, D.J., Novy, D.M., \& Liberman, D. (1991). How letter-sound 
instruction mediates progress in first grade reading and spelling. Journal of Educational Psychology, 83, 456-469.

Frith, U. (1979). Reading by eye and writing by ear. In P. Kolers, M. Wrolstad, \& H. Bouma (Eds.), Processing of Visible Language, vol. 1. (pp. 379-390). Plenum Publishing Corporation.

Frith U. (1980). Unexpected spelling problems. In U. Frith (Ed.), Cognitive processes in spelling (pp. 495-515). London: Academic Press.

Frith, U. (1985). Beneath the surface of developmental dyslexia. In K.E. Patterson, J.C. Marshall, \& M. Coltheart (Eds.), Surface dyslexia: Neuropsychological and cognitive studies of phonological reading (pp. 301-330). London: Erlbaum.

Frost, R., Katz, L., \& Bentin, S. (1987). Strategies for visual word recognition and orthographical depth: A multilingual comparison. Journal of Experimental Psychology, Human Perception and performance, 13, 104-115.

Gholamain, M., \& Geva, E. (1999). Orthographic and cognitive factors in concurrent development of basic reading skills in English and Persian. Language Learning, 49,183-217.

Goswami, U., \& Bryant, P.E. (1990). Phonological skills in learning to read. Hillsdale, NJ: Lawrence Erlbaum Assoc.

Goswami, U., Porpodas, C., \& Wheelwright, S. (1997). Children's orthographic representations in English and Greek. European Journal of Psychology of Education, 3, 273-292.

Goswami, U., Gombert, J.E., Barrera, L.F. (1998). Children's orthographic representations and linguistic transparency: Nonsense word reading in English, 
French, and Spanish. Applied Psycholinguistics, 19, 19-52.

Goswami, U., Ziegler, J.C., Dalton, L., \& Schneider, W. (2003). Nonword reading across orthographies: How flexible is the choice of reading units ? Applied Psycholinguistics, 24, 235-247.

Goswami, U. (1988). Orthographic analogies and reading development. The Quarterly Journal of Experimental Psychology, 40(2), 239-268.

Goswami, U. (1990). Phonological priming and orthographic analogies in reading. Journal of Experimental Child Psychology, 49, 323-340.

Goswami, U. (1993). Toward an interactive analogy of model of reading development: Decoding vowel graphemes in beginning reading. Journal of Experimental Child Psychology, 56, 443-475.

Holopainen, L., Ahonen, T., \& Lyytinen, H. (2005). Development of reading and linguistic abilities. Results from a Finnish longitudinal study. Manuscript submitted for publication.

Jared, D. (1997). Spelling-sound consistency affects the naming of high-frequency words. Journal of Memory and Language, 4, 723-750.

Job, R., Peressotti, F., \& Mulatti, C. (2006). The acquisition of literacy in Italian. In R. M. Joshi \& P.G. Aaron (Eds.), Hand book of orthography and literacy (pp. 105119). NJ: Lawrence Erlbaum Associates.

Job, R. (1994). Development of reading and writing in Italian. Paper presented at the NATO Advanced Study Institute on Cognitive and Linguistic Bases of Reading. Writing and Spelling. Algarve, Portugal. Juel, C., Griffith, P.L., \& Gough, P.B. (1986). Acquisition of literacy: A longitudinal 
study of children in first and second grade. Journal of Educational Psychology, 4, 243-255.

Juel, C. (1988). Learning to read and write: A longitudinal study of 54 children from first through fourth grades. Journal of Educational Psychology, 80, 4, 437-447.

Juul, H. (2005). Knowledge of context sensitive spellings as a component of spelling competence: Evidence from Danish. Applied Psycholinguistics 26, 249-265.

Katz, L., \& Frost, R. (1992). The reading process is different for different orthographies: The orthographic depth hypothesis. In R. Frost \& L. Katz (Eds.), Orthography, phonology, morphology, and meaning (pp. 67-84). Amsterdam: Elsevier.

Katz, L., \& Feldman, L. B. (1983). Relation between pronunciation and recognition of printed words in deep and shallow orthographies. Journal of Experimental Psychology: Learning Memory and Cognition, 9, 157-166.

Kinoshita, S., \& Lupker, S.J., Rastle, K., (2004). Modulation of regularity and lexicality effects in reading aloud. Memory and Cognition, 32, 1255-1264.

Kwong, T.E., \& Varnhagen, C.K. (2005). Strategy development and learning to spell new words: Generalizaation of a Process. Developmental Psychology, 41(1), 148159.

Kyte, C.S., \& Johnson, C.J. (2006). The role of phonological recoding in orthographic learning. Journal of Experimental Child Psychology 93, 166-185.

Lehtonen, A. (2006). Sources of information children use in learning to spell: The case of Finnish Geminates. In R. M. Joshi \& P. G. Aaron (Eds.). Handbook of orthography and literacy (pp. 63-79). London: Lawrence Erlbaum Associates. Leppanen,U., Niemi,P., Aunola, K., \& Nurmi, J.E. (2006). Development of reading and 
spelling Finnish from preschool to Grade 1 and Grade 2. Scientific studies of reading, 10 (1), 3-30.

Lerkkanene, M.K., Rasku-Puttonen, H., Aunola, A., \& Nurmi, J.E. (2004). The developmental dynamics of literacy skills during the first grade. Educational Psychology, 24 (6), 793-810.

Lexon, V.J., Coltheart, V., \& Keating, C. (1988). Children find friendly words friendly too. Words with many orthographic neighbours are easier to read and spell. British Journal of Educational Psychology, 58, 103-119.

Lundberg, I., Olofsson, A., \& Wall, S. (1980). Reading and spelling skills in the first school years predicted from phonemic awareness skills in kindergarten. Scandinavian Journal of Psychology, 21, 159-173.

Majidi, M.M., \& Terens, E. (1999). Persian (Farsi). In Handbook of the International Phonetic Association: A guide to the International Phonetic Alphabet (pp. 124125). Cambridge University Press.

Malmquist, E. (1958). Factors related to reading disabilities in the first grade of the elementary school. Stockholm: Malmquist and Wiksell.

Marsh, G., Desberg, P., \& Cooper, J. (1997). Developmental strategies in reading. Journal of Reading Behavior, 9, 391-394.

Olson, R.k., Wise, B., Connert. F., Rack, J., \& Fulker, D. (1989). Specific deficits in component reading and language skills: Genetic and environmental influences. Journal of learning Disabilities, 22, 339-348.

Oney, B., \& Durgunoglu, A.Y. (1997). Learning to read in Turkish: A phonologically transparent orthography. Applied Psycholinguistic, 18, 1-15. 
Pacton, S., Perruchet, P., Fayol, M., \& Cleeremans, A. (2001). Implicit learning out of the Lab: The case of orthographic regularities. Journal of Experimental Psychology: General, 130, 401-426.

Perfetti, C.A., Beck, I., Bell, L.C., \& Hughes, C. (1987). Phonemic knowledge and learning to read are reciprocal: A longitudinal study of first grade children. Merrill-Palmer Quarterly, 33, 283-319.

Perfetti, C.A. (1985). Reading ability. New York: Oxford University Press.

Perry, C., \& Ziegler, J.C. (2004). Beyond the Two-strategy model of skilled spelling: Effects of consistency, grain size, and orthographic redundancy. Quarterly Journal of Experimental Psychology, 57, 325-356.

Perry, C., \& Ziegler, J.C. (2000). Linguistic difficulties in language and reading development constrain skilled adult reading. Memory and Cognition, 28,739-745.

Pinheiro, A.M.V. (1995). Reading and spelling development in Brazilian Portuguese. Reading and Writing: An Interdisciplinary Journal 7, 111-138.

Porpodas, C.D. (1989a). The phonological factor in reading and spelling of Greek. In P. G. Aaron \& R. M. Joshi (Eds.), Reading and writing disorders in different orthographic systems (pp. 177-190). Dordrecht, Netherlands: Kluwer.

Porpodas, C. (2001). Cognitive processes in first grade reading and spelling of Greek. Psychology: The Journal of the Hellenic Psychology Society-A special issue devoted to Research on Reading, Spelling and Dyslexia in Europe, 8, 384-400.

Rahbari, N., Sénéchal, M., \& Arab-Moghaddam, N, (2007). The role of visual and phonological processing skills in reading and spelling of monolingual Persian children. Reading and Writing: An Interdisciplinary Journal, 20, 511-533. 
Rahbari, N., \& Sénéchal, M. (2008). Lexical and nonlexical processes in the skilled reading and spelling of Persian. Available online in the Journal of Reading and Writing.

Raman, I., Baluch, B., \& Besner, D. (2004). On the control of visual word recognition: Changing routes versus changing deadlines. Memory and Cognition, 32, 489-500.

Raman, I., \& Weekes, B. (2005). Acquired dyslexia in a Turkish-English speaker. Annals of Dyslexia, 55, 79-104.

Rittle-Johnson, B., \& Siegler, R. S. (1999). Learning to spell: Variability, choice, and change in children's strategy use. Child Development, 70, 332-348.

Seymour, P.H.K., \& Elder, L. (1986). Beginning reading without phonology. Cognitive Neuropsychology, 3, 1-36.

Seymour, P.H.K., Aro, M., \& Erskine, J.M. (2003). Foundation literacy acquisition in European orthographies. British Journal of Psychology, 94, 143-174.

Share, D.L., \& Stanovich, K.E. (1995). Cognitive processing in early reading development: Accommodating individual differences in to a model of Acquisition. Issue in Education: Contributions from Educational psychology, 1, $1-57$.

Share, D.L. (1995). Phonological recoding and self-teaching: sine qua non of reading acquisition. Cognition 55, 151-218.

Share, D.L. (1999). Phonological recoding and orthographic learning: A direct test of self-teaching hypothesis. Journal of experimental child psychology, 29, 294-305.

Share, D.L. (2004). Orthographic learning in a glance: On the time course and developmental onset of self-teaching. Journal of experimental child psychology, 87, 267-298. 
Shanahan, T., \& Lomax R.G. (1986). An analysis and comparison of theoretical models of the reading-writing relationship. Journal of Educational Psychology, 78, 116123.

Spencer, H.L., \& Hanley, R. (2003). Effects of orthographic transparency on reading and phoneme awareness in children learning to read in Wales. British Journal of Psychology, 94,1-28.

Sprenger-Charolles, L., \& Casalis, S. (1995). Reading and spelling acquisition in French first graders: Longitudinal evidence. Reading and Writing: An Interdisciplinary Journal, 7, 1-25.

Sprenger-Charolles, L., Siegel, L. S., \& Bonnet, P. (1998). Reading and spellin acquisition in French: The role of phonological mediation and orthographic factors. Journal of Experimental Child Psychology, 68,134-165.

Sprenger-Charolles, L.,Siegel, L. S., Bechennec, D., \& Serniclaes, W. (2003).

Development of phonological and orthographic processing in reading aloud, in silent reading, and in spelling: A four-year longitudinal study. $J$. Experimental Child Psychology, 84,194-217.

Sprenger-Charolles, L. (2003). Linguistic processes in reading and spelling: The case of alphabetic writing systems: English, French, German and Spanish. In T. Nunes \& P. Bryant (Eds.), Handbook of children's literacy (pp. 43-65). The Netherlands, Kluwer.

Stage, S.A., \& Wagner, R.K. (1992). Development of young children's phonological and orthographic knowledge as revealed by their spellings. Developmental psychology, 28, 28-296. 
Stanovich, K.E., \& Siegel, L.S. (1994). Phenotypic performance profile of children with reading disabilities: A regression-based test of the phonological-core variabledifference model. Journal of Educational Psychology, 86, 24-53.

Stanovich, K.E. (1980). Toward an interactive-compensatory model of individual differences in the development of reading fluency. Reading Quarterly, 16, 32-71.

Stuart, M., Coltheart, M. (1988). Does reading develop in a sequence of stages? Cognition, 30, 139-181.

Thorstad, G. (1991). The effect of orthography in the acquisition of literacy skills. British Journal of Psychology, 82, 527-537.

Treiman, R., Cassar, M., \& Zukowski, A. (1994). What types of linguistic information do children use in spelling? The case of flaps. Child Development, 65, 1310-1329.

Treiman, R. (1993). Beginning to spell. New York: Oxford University Press.

Ventura, P., Morais, J., Pattamadilok, C., \& Kolinsky, R. (2004). The locus of the orthographic consistency effect in auditory word recognition. Language and Cognitive Processes, 19, 57-95.

Verhoeven, L., Baayen, H., \& Scheruder, R. (2004). Orthographic constraints and frequency effects in complex word identification. Written Language and Literacy, 7, 49-59.

Waters, G.S., Seidenberg, M. S., \& Bruck, M. (1984). Children's and adult's use of spelling-sound information in three reading tasks. Memory and Cognition, 12, 293-305.

Weekes, B. S., Castles, A. E., \& Davies, R. A. (2006). Effects of consistency and age of 
acquisition on reading and spelling among developing readers. Reading and Writing, 19, 133-169.

Wimmer, H., \& Hummer, P. (1990). How German-speaking first graders read and spell: Doubts on the importance of the Logographic stage. Applied Psycholinguistics, $11,349-368$.

Wimmer, H., Goswami, U. (1994). The influence of orthographic consistency on reading development: Word recognition in English and German children. Cognition, 51, 91-103.

Wimmer, H., \& Mayringer, H. (2002). Dysfluent reading in the absence of spelling difficulties: A specific disability in regular orthographies. Journal of Educational Psychology, 94, 272-277.

Wimmer, H., \& Landerl, K. (1997). How learning to spell German differs from learning to spell English. In C.A. Perfetti, L. Rieben, \&M. Fayol (Eds.), Learning to spell: Research, theory and practice across languages. Mahwah, NJ: Erlbaum.

Wydell, T.N., Butterworth, B. (1999). A case study of an English-Japanese bilingual with monolingual dyslexia. Cognition, 70, 273-305.

Ziegler, J.C., Jacobs, A.M., \& Stone, G.O. (1996). Statistical analysis of the bidirectional inconsistency of spelling and sound in French. Behavior Research Methods, Instruments, \& Computers, 28, 504-515.

Ziegler, J.C., Stone, G.O., \& Jacobs, A.M. (1997). What's the pronunciation for OUGH and the spelling for $/ \mathrm{u} /$ ? A database for computing feedforward and feedback inconsistency in English. Behavior Research Methods, Instruments, \& Computers, 29, 600-618. 
Ziegler, J.C., Ferrand, L., \& Montant, M. (2004). Visual phonology: The effects of orthographic consistency on different auditory word recognition tasks. Memory and Cognition, 32, 732-741. 
APPANDICES 
Appendix A: List of Real Words (60) for Reading and Spelling with Frequencies, and Durations (in milliseconds).

\begin{tabular}{|c|c|c|c|c|c|c|}
\hline \multirow[t]{2}{*}{ Type of words } & \multicolumn{3}{|c|}{ Transparent } & \multicolumn{3}{|c|}{ Opaque } \\
\hline & Persian spelling & Frequencies & Duration & Persian spelling & Frequencies & Duration \\
\hline \multirow{15}{*}{$\begin{array}{c}\text { Non- } \\
\text { polygraphic }\end{array}$} & ديك & 2.20 & 603 & كشف & 4.46 & 692 \\
\hline & ريك & 3.15 & 829 & كري & 3.85 & 658 \\
\hline & بيتيج & 3.35 & 795 & كنج & 2.63 & 759 \\
\hline & خام & 3.35 & 707 & شرمَ & 3.01 & 739 \\
\hline & بيم & 3.01 & 624 & بلك & 3.20 & 679 \\
\hline & باك & 5.85 & 713 & جلبك & 2.71 & 933 \\
\hline & يير & 4.45 & 663 & لِشم & 4.02 & 642 \\
\hline & ميخ & 3.36 & 663 & مرك & 4.10 & 768 \\
\hline & كاخ & 3.65 & 645 & خرج & 3.95 & 745 \\
\hline & جارى & 3.21 & 861 & كشك & 3.15 & 827 \\
\hline & خن & 4.55 & 621 & ل بخش & 3.75 & 666 \\
\hline & كيج & 2.45 & 590 & كنج & 3.82 & 686 \\
\hline & كمد & 2.80 & 607 & كبك & 2.50 & 661 \\
\hline & كوت & 3.62 & 742 & حرب & 3.23 & 789 \\
\hline & شُود & 3.75 & 787 & جشن & 4.75 & 771 \\
\hline \multirow{15}{*}{ polygraphic } & 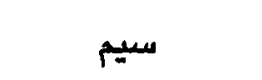 & 3.55 & 665 & غرق & 3.25 & 710 \\
\hline & قيف & 2.82 & 616 & سقف & 3.45 & 884 \\
\hline & ناز & 3.75 & 718 & قطب & 2.93 & 570 \\
\hline & راز & 4.73 & 678 & ثبت & 2.01 & 732 \\
\hline & زاغ & 3.01 & 715 & سهل & 2.62 & 811 \\
\hline & كاف & 3.45 & 883 & صلح & 4.25 & 802 \\
\hline & سود & 3.95 & 869 & ذهن & 3.15 & 780 \\
\hline & سوت & 3.75 & 803 & شرط & 3.92 & 786 \\
\hline & جاق & 3.80 & 710 & شعفت & 4.25 & 927 \\
\hline & باغ & 5.64 & 646 & ضبط & 3.01 & 766 \\
\hline & تاج & 2.60 & 779 & هتر & 3.62 & 715 \\
\hline & داغٔ & 3.54 & 697 & ربط & 3.15 & 710 \\
\hline & قاضى & 4.42 & 867 & نقص & 2.95 & 585 \\
\hline & كاز & 3.00 & 610 & قرض & 3.50 & 637 \\
\hline & تيغ & 2.45 & 810 & قصد & 3.92 & 700 \\
\hline
\end{tabular}

* The pronunciation of words in IPA and English Meanings are presented in the next page 
Persian Words, pronunciations in IPA and English Meanings

\begin{tabular}{|c|c|c|c|c|c|}
\hline Persian spelling & IPA & Meaning & Persian spelling & IPA & Meaning \\
\hline ديك & /dig/ & pot & كشف & $/ k æ \int f /$ & discovery \\
\hline ريك & /rig/ & gravel & كرك & /gorg/ & wolf \\
\hline ييّج & /pitf/ & screw & كنج & /kondzl & corner \\
\hline خام & /xām/ & raw & شرم & 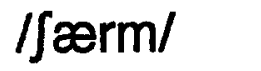 & shame \\
\hline بيم & /bim/ & fear & يلك & /pelk/ & eyelid \\
\hline ياك & /pāk/ & clean & جلبك & /dzolbæk/ & alga \\
\hline يير & /pir/ & old & & $/ p æ \int m /$ & wool \\
\hline ميخ & $/ \mathrm{mix} /$ & nail & مرك & /mærg/ & death \\
\hline كاخ & /kāx/ & palace & خرج & /xærdz/ & expense \\
\hline جارى & /dzāry/ & flow & كشك & /kæ $\int k J$ & dried whey \\
\hline خضن & /xun/ & blood & بخش & /pækh J/ & broadcast \\
\hline كيج & /gidz/ & confused & ن & /gændz/ & treasure \\
\hline كقد & /gur/ & grave & كبك & /kæbk/ & partridge \\
\hline كوع & /kutf/ & migration & جرب & /tfærb/ & oily \\
\hline شود & / Sur/ & salty & جشن & /dzæen/ & festival \\
\hline سيم مي & /sim/ & wire & غرق & /værG/ & sink \\
\hline قيف & /Gif/ & funnel & سقف & /sæGf/ & ceiling \\
\hline ناز & /nāzl & cute & & /Gotb/ & pole \\
\hline راز & /rāzl & secret & & /sæbt/ & registration \\
\hline زأ & /zay/ & crow & سـهل & /sæhl/ & easy \\
\hline صاف & /sāf/ & smooth & صلح & /solh/ & peace \\
\hline سود & /sud/ & benefit & ذهن & /zehn/ & mind \\
\hline سوت & /sut/ & whistle & شرط & 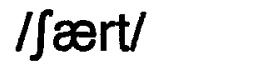 & condition \\
\hline جاق & /țāG/ & fat & شكفت & /Segeft/ & wonder \\
\hline غب & /bāy/ & garden & ضبط & /zæbt/ & record \\
\hline تاج & /tāj/ & crown & هتر & /fætr/ & umbrella \\
\hline$\varepsilon^{\prime l}$ & /dāy/ & hot & ربط & /ræbt/ & connection \\
\hline قاضلى & /Gāzi// & judge & نقص & /næGs/ & deficiency \\
\hline كاز & /gāz/ & gas & قرض & /Gærz/ & debt \\
\hline تين & /tiy/ & thorn & قهد & /Gæsd/ & purpose \\
\hline
\end{tabular}


Appendix B: List of Nonwords (40) for Reading and Spelling

\begin{tabular}{|c|c|c|c|}
\hline \multicolumn{2}{|c|}{ Non-words } & \multicolumn{2}{|c|}{ Non-words } \\
\hline Persian spelling & IPA & Persian spelling & IPA \\
\hline ريب & /rib/ & خابو & |xābool \\
\hline ميكي & /mig/ & ماخ & Māxl \\
\hline لوج & /udł! & شار & / $\int \bar{a}$ r/ \\
\hline لاب & 凡āb/ & فيل & /fid/ \\
\hline راز & /räz/ & نال & Ināll \\
\hline راب & /rāb/ & لديز & /diz' \\
\hline خيم & Ixhim/ & مازٌ ماز & /māzl \\
\hline باج & /pādz/ & جاب & /dzāab/ \\
\hline جود & trud/ & شيل & $/ \mathrm{fi} / /$ \\
\hline داك & /dāk/ & مام & /țām/ \\
\hline ذير & /3ir/ & واش & /vāJI \\
\hline جوج & /dzudz/ & لولد & hud/ \\
\hline جاد & & ريم & /rim/ \\
\hline$\therefore$ & & als & /daf/ \\
\hline نوخ & InuxI & داف & raall \\
\hline ديل & /dil/ & راجا & /rādzā/ \\
\hline لاد & /ād/ & ثيد & /3id/ \\
\hline خاز & khāzl & لا & /āx \\
\hline راك & Irāk & ريف & /rif \\
\hline ديخ & thive & 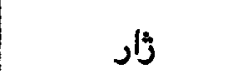 & |zāar/ \\
\hline بون & /bux/ & ذوكي & /3ukI \\
\hline
\end{tabular}


Appendix c: Persian Alphabet

\begin{tabular}{|c|c|c|c|c|c|}
\hline Letters & Names & Sounds in IPA & Letters & Names & Sounds in IPA \\
\hline i & alef & [D] & ص & sād & [s] \\
\hline ب & be & [b] & ض & zād & [z] \\
\hline ب & pe & [p] & b & tā & {$[t]$} \\
\hline ت & te & {$[t]$} & ظ & zāa & [z] \\
\hline 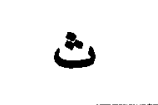 & se & [s] & $\varepsilon$ & eyn & [?] \\
\hline T & $\mathrm{jim}$ & [d]] & $\dot{\varepsilon}$ & qeyn & {$[\gamma] /[c]$} \\
\hline Е & che & {$[t]$} & فـ & fe & [f] \\
\hline$\tau$ & he & [h] & ق & qāf & {$[q] /[c]$} \\
\hline$\dot{\tau}$ & khe & {$[x]$} & S & kāf & [k] \\
\hline J & dāl & [d] & $s$ & gāf & [g] \\
\hline$j$ & zāl & [z] & J & lām & [l] \\
\hline J & re & {$[r]$} & $\hat{\boldsymbol{r}}$ & $\mathrm{mim}$ & [m] \\
\hline j & ze & [z] & $\dot{ن}$ & nun & [n] \\
\hline$j$ & zhe & [3] & و & vāv & {$[v] /[u]$} \\
\hline س & $\sin$ & [s] & $\Delta$ & he & [h] \\
\hline ش & shin & []] & 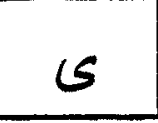 & ye & [i] , [i] \\
\hline
\end{tabular}

*Note that the symbol $\overline{\mathbf{a}}$ in some letter names is corresponds to the sound /D:/ 